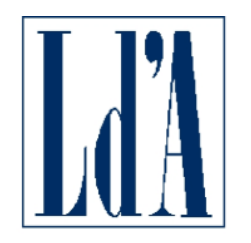

CENTRO STUDI LUCA D'AGLIANO

WWW.DAGLIANO.UNIMI.IT

\author{
CENTRO STUDI LUCA D'AGLIANO \\ DEVELOPMENT STUDIES WORKING PAPERS
}

N. 423

February 2017

Risk Attitudes and Household Migration Decisions

\author{
Christian Dustmann* \\ Francesco Fasani** \\ Xin Meng*** \\ Luigi Minale ****
}

* University College London and CReAM

** Queen Mary University of London, CReAM, CEPR and IZA

*** Australian National University, CReAM and IZA

**** Universidad Carlos III de Madrid, CReAM and IZA 


\title{
Risk Attitudes and Household Migration Decisions
}

\author{
Christian Dustmann (University College London and CReAM), Francesco Fasani (Queen \\ Mary University of London, CReAM, CEPR and IZA), Xin Meng (Australian National \\ University, CReAM and IZA) and Luigi Minale (Universidad Carlos III de Madrid, CReAM \\ and IZA)
}

February $2017^{1}$

\begin{abstract}
This paper analyses the relation between individual migrations and the risk attitudes of other household members when migration is a household decision. We develop a simple model that implies that which member migrates depends on the distribution of risk attitudes among all household members, and that the risk diversification gain to other household members may induce migrations that would not take place in an individual framework. Using unique data for China on risk attitudes of internal (rural-urban) migrants and the families left behind, we empirically test three key implications of the model: (i) that conditional on migration gains, less risk averse individuals are more likely to migrate; (ii) that within households, the least risk averse individual is more likely to emigrate; and (iii) that across households, the most risk averse households are more likely to send migrants as long as they have at least one family member with sufficiently low risk aversion. Our results not only provide evidence that migration decisions are taken on a household level but also that the distribution of risk attitudes within the household affects whether a migration takes place and who will emigrate.
\end{abstract}

JEL classification: J61, 015, R23, D81

Keywords: risk aversion, internal migration, household decisions

\footnotetext{
${ }^{1}$ This paper has been prepared within the "Value added in motion" project funded by the Enel Foundation.
} 


\section{Introduction}

A recent and growing body of empirical literature suggests that individual risk aversion has a significant impact on a wide range of individual choices, including portfolio diversification, engagement in healthy behaviours, occupational choices, wealth accumulation, technology adoption and migration decisions (see, among others, Barsky et al., 1997; Bonin et al., 2007; Guiso \& Paiella, 2008; Dohmen et al., 2011; Liu, 2013; Jaeger et al. 2010). All these papers explore the relationship between individual decision making and the individual's own risk aversion. However, when decisions are taken at the household level, the benefit of risk diversification to the more risk averse household members may also influence the decisions of one particular member. One context in which other household members' risk aversion may affect the behaviour of one focal individual is rural-urban migration in developing countries. ${ }^{2}$

In this paper, we analyse how the probability of a household sending a migrant depends on the distribution of risk attitudes within the household. In doing so, we focus on three aspects. First, we re-examine whether migrants are indeed less risk averse than non-migrants. Second, we investigate whether the risk aversion of other household members affects who emigrates from a particular household. Finally, we analyse which households send migrants and how this choice depends on the distribution of risk aversion among household members, as well as on the individual risk aversion of the potential emigrants.

To structure our empirical investigation, we develop a theoretical framework of household migration decisions from which to derive a set of testable implications. Our model draws on an earlier literature on household migration decisions and risk (e.g. Stark \& Levhari, 1982; Hoddinott, 1994), but is most closely related to Chen et al. (2003). We add to this work by introducing heterogeneous risk preferences among family members in a setting in which the

\footnotetext{
${ }^{2}$ There exists a body of literature suggesting that migrations in this context may be driven by motives of risk diversification (see e.g. Rosenzweig \& Stark, 1989). However, these papers do not speak to the question as to how the distribution of risk attitudes within the household affects migration decisions.
} 
family chooses not only whether to send a migrant but also whom to send. ${ }^{3}$ Our model provides us with testable implications on migrant selection at the individual level, both within households and across households. We then test the model predictions on migrant selection, using survey data on internal migration in China, a country that has experienced massive migration flows from rural to urban areas in recent years. As we explain in section II, the Chinese institutional setting makes household decision models a particularly appropriate tool for analysing internal migration (see also Rozelle et al, 1999, and Taylor et al, 2003). We base our analysis on a unique dataset that elicit willingness to take risks from both migrants and non-migrant family members. The reliability of this measure has been experimentally validated.

We find that individuals who migrate are less risk averse than those who do not migrate. This result lends further support to the findings of Jaeger et al. (2010) and Gibson and McKenzie (2011) for internal migration in Germany and international migration to New Zealand, respectively. Our estimates further imply that rural-urban migrations in the context of a large developing country such as China, are considered to be risky. This adds to findings by Bryan et al. (2014) who show that the uncertainty associated with internal migration in Bangladesh creates a barrier to migration, despite large gains and relatively small costs.

We then investigate how migration decisions of one household member are affected by the risk aversion of other household members. In line with our model, we show that individuals who are the least risk averse in their households are more likely to migrate than those with identical risk aversion but who are not the least risk averse in their household. At the household level, we find that more risk averse households are more likely to send migrants - consistently with migration as risk diversification strategy - but only if they have at least one household

\footnotetext{
${ }^{3}$ Only few papers study risk sharing when preferences are heterogeneous across households (Mazzocco and Saini, 2012; Chiappori et al., 2014) or within households (Mazzocco, 2004), but none of them studies migration decisions.
} 
member who is sufficiently risk loving. These results suggest that internal rural-urban migration in China is a household decision and that the distribution of risk aversion within households is an important additional factor determining the selection of individuals and households into migration.

This role of risk diversification in migration decisions has been previously explored in the migration literature both when the migration decision is an individual choice (e.g. Dustmann, 1997) and when it is made at the household level (see e.g. Stark \& Levhari, 1982; Rosenzweig \& Stark, 1989; Chen et al., 2003; Morten, 2013; Gröger and Zylberberg, 2016; Munshi and Rosenzweig, 2016). ${ }^{4}$ Nevertheless, although these papers pinpoint risk diversification as a key element in a household's decision problem, they do not investigate the relation between risk attitudes and migration choices within and across household units nor do they discuss how the distribution of risk attitudes within households may affect the migration decision. Yet understanding who emigrates, how emigrants compare with other household members, and which households send migrants is crucial for assessing determinants and consequences of migration. Such an understanding is central, for example, to the issue of migrant selection based on unobservable characteristics determining productivity, which has important economic consequences for both receiving and sending communities (see e.g. Borjas, 1987; Borjas and Bratsberg, 1996; Chiquiar \& Hanson, 2005; McKenzie \& Rapoport 2010; Dustmann, Fadlon $\&$ Weiss, 2011). To date, however, such selection has been addressed primarily using models of individual migration decisions. Our analysis, in contrast, employs a household-level migration decision model to show that the risk preferences of other household members and their distribution within the household may not only determine who and how many emigrate

\footnotetext{
${ }^{4}$ The importance of household migration decisions as mechanisms to cope with unexpected negative shocks is illustrated by Jalan and Ravallion (1999) for rural China, who show the poorest households passing up to $40 \%$ of income shocks onto current consumption. Further, Giles (2006) and Giles and Yoo (2007) show that the liberalization of internal migration flows in China in the early ' 90 s provided rural household with a new mechanism to hedge against consumption risk.
} 
but also the level of risk aversion of the migrant population. This latter point is especially important in the face of recent findings that risk aversion is negatively correlated with both cognitive ability (Dohmen et al. 2010) and the probability of engaging in entrepreneurial activity (Ekelund, Johansson, \& Lichtermann, 2005; Levine \& Rubinstein 2014), which point to it being a key factor determining immigrant success.

The remainder of the paper is organized as follows. Section II describes the institutional background of internal migration in China. Section III outlines our theoretical framework for the relation between individual risk aversion and the household decision of whether to send a migrant and whom to send, and then develops the empirical implications of this relation. Section IV describes the -data and reports descriptive statistics. Section V explains our empirical strategy and reports the estimation results. Section VI provides a simulation exercise. Section VII concludes the paper.

\section{Internal Migration in China}

In the late 1970s, rural communities in China moved from a "commune system" to a "household responsibility system" under which households, which were allocated land use rights, could choose their own crops, and were allowed to sell their produce freely on the market subject to fulfilment of government taxes. While this shift significantly increased agricultural productivity, many basic social services provided by the communes were abolished, so households found themselves in the situation of having to finance their own health and education, as well as having to deal with other unforeseeable risks, such as adverse weather conditions. This change increased the need to diversify the sources of household income, but before the early 1990s, such diversification was limited by relatively strict rural-urban segregation enforced through a household registration system (or hukou) that gave people the right to live only in the jurisdiction of their birth (see Meng, 2012). It was not until the late 1990s, when the massive economic development of urban areas created a significant increase 
in demand for unskilled labour that the government began to loosen its enforcement of migration restrictions. Internal mobility rapidly increased. According to data from the Chinese National Bureau of Statistics (NBS), the total number of rural-urban migrants increased from around 30 million in 1996 to 150 million in 2009 , a rise from 2.5 to $11 \%$ of the total population.

Despite the relaxation of migration restrictions, migrants in cities are treated as guest workers: they are still largely excluded from social services and social insurances which are available to urban hukou holders (Meng \& Manning, 2010). For instance, migrants (and their dependents) are not covered by the city health care system in case of illness and their children are excluded from urban local schools. In response to such an institutional setting, internal migration in China has predominantly been characterized by individual, temporary and circular movements back and forth from rural to urban areas.

Another important institutional arrangement which reinforces these traits of rural-urban migration is the Chinese land tenure system. Land is collectively owned in rural China and allocated to households by local and village authorities who can then decide to repossess and reassign the plots. Farmers are entitled to use their allocated land but they cannot resell it. In order to maintain the household entitlement to the land - which is the only safety net for all its members - some of the household members must remain in rural areas to farm it (Giles and $\mathrm{Mu}, 2014)$.

As a result of these two institutional arrangements, both the permanent settlement of migrants in urban areas and the migration of entire households from rural areas is rarely observed in China. Most migrants leave their family members behind and maintain close links. ${ }^{5}$ Repeated short term migration spells are common. In our sample, migrants spend an average 9.6 months per year working in destination regions and the remaining 2.4 months at home (see

\footnotetext{
${ }^{5}$ On average, migrants send back $10-15 \%$ of their urban per capita income. For those with left-behind spouse or children, transfers increase to $20-25 \%$ of per capita urban income. (Meng et. al., 2016).
} 
section IV). These institutional settings make household decision models a particularly appropriate tool for analysing internal migration in China.

According to the Chinese National Bureau of Statistics, per capita net income in urban and rural areas in the year 2009 (the year our survey data were collected; see section IV) was 17.2 and 5.1 thousand yuan, respectively. This income gap reflects the gap between the average rural hukou households in rural areas and urban hukou households, and most likely overstates the gain in earnings experienced by rural migrants in Chinese cities. Migrants, indeed, are unable to obtain most of the type of jobs available to an average urban hukou local worker, being confined to occupations at the lower end of the distribution of urban jobs. According to the 2009 migrant survey of the RUMIC survey (the data we use in this paper; see section IV), migrants earn 1800 yuan per month in urban areas, approximately 2.2 times their estimated earnings in rural areas (i.e. 800 yuan).

Despite this sizeable income gap, life in cities is hard for Chinese internal migrants. They give up on whatever social services and insurances they had in rural areas to move to places where most of these services and insurances are not available to them. In addition, most migrants in cities are engaged in 3D (dirty, dangerous, and demeaning) jobs that their urban local counterparts are unwilling to take (see Meng and Zhang, 2001 and Meng, 2012). In particular, they are disproportionally exposed to hazardous environments, being more likely to work in high-risk occupations (e.g. construction, chemical industries), having strenuous working schedule, lacking safety equipment and coverage with occupational injury insurance (Zhao et al. 2012; Frijters et. al. 2011), and migrants receive lower pay even within the same occupation (Frijters et. al. 2015 and Meng \& Zhang, 2001). These working conditions combined with poor housing and no access to health care contributes to generating serious health hazards (Du et al., 2005). When jobs are scarce, rural migrants are usually the first group of workers to be laid off (Meng and Zhang, 2010). Lacking any unemployment insurance, rural 
migrants are particularly vulnerable during unemployment spells and may be forced to return home to avoid starvation. Income variance is large also for migrants in employment. According to data from the 2009 RUMIC migrant survey (see section IV), migrants' monthly earnings have a coefficient of variation close to 1 , whereas for the earnings they would have expected to make in their hometown, the coefficient variation is only 0.58 .

Thus, although China resembles other developing countries in having a sizeable rural-urban income gap that motivates internal migration, the Chinese unique institutional setting seems to expose its rural migrants in cities to far greater uncertainties and risks.

\section{A Model of Household Migration Decision with Individual}

\section{Heterogeneity in Risk Aversion}

We now develop a model of household migration decisions that captures the distinct features of internal migration in China we just described.

\section{A. Setup}

We denote individual earnings by $y_{j}$, where $j=S, D$ for source $(S)$ and destination $(D)$ region, and assign earnings a deterministic component $\bar{y}_{j}$ and a stochastic component $\epsilon_{j}$, with $E\left(\epsilon_{j}\right)=$ $0 ; V\left(\varepsilon_{j}\right)=\sigma_{j}^{2}$ for $j=S, D$. We further assume that shocks in source and destination regions are uncorrelated: $\operatorname{Cov}\left(\varepsilon_{S} \varepsilon_{D}\right)=0 .{ }^{6}$ Migration to region $D$ incurs a monetary cost $c$ that is heterogeneous across households but homogenous within households. ${ }^{7}$ Earnings in the two regions are thus

$$
\begin{gathered}
y_{S}=\bar{y}_{\mathrm{S}}+\varepsilon_{S} \\
y_{D}=\bar{y}_{\mathrm{D}}-c+\varepsilon_{D}
\end{gathered}
$$

\footnotetext{
${ }^{6}$ Allowing for a non-zero correlation between shocks in source and destination regions does not change any of our conclusions (see Appendix section A.I.C) but does complicate our analysis.

${ }^{7}$ Households may be heterogeneous in wealth, access to credit, distance from the destination region, etc. but the monetary cost of financing the migration of one member or the other does not differ within household.
} 
Each household consists of two members who can perfectly pool their income only if they are both residing in the same origin region $S .{ }^{8}$ Perfect income pooling reflects the fact that household members live in the same house and fully share all resources. We use $\tilde{Y}$ to denote total pooled household income and $\tilde{y}$ to represent the amount each individual receives from the pooled income. If both members stay in $S$, the total pooled household income is given by $\tilde{Y}_{S S}=$ $2 y_{S}$, and each individual receives exactly $\tilde{y}_{S S}=y_{S}$.

If one individual migrates, distance will only allow imperfect income pooling. This assumption is justified by the fact that, while in urban areas, the migrant will employ part of her income to cover her expenses (rent, food, etc.) and will not enjoy immediate access to household resources (housing, agricultural products, etc.) in the origin area. In particular, we assume that the member who remains in region $S$ will still pool her entire income $y_{S}$ and receive a full quota of the total pooled income, while the member who migrates to region $D$ will only contribute a fraction $\alpha$ of earnings $y_{D}$ and will receive the same fraction $\alpha$ of the full quota. Hence, total pooled income if one household member has emigrated is given by $\tilde{Y}_{S D}=y_{S}+$ $\alpha y_{D}$. Defining $\tilde{y}^{N M}$ and $\tilde{y}^{M}$ as the individual disposable income of the non-migrant (NM) and migrant (M) household member, respectively, yields:

$$
\begin{gathered}
\tilde{y}^{N M}=\tilde{Y}_{S D} /(1+\alpha) \\
\tilde{y}^{M}=\alpha\left[\tilde{Y}_{S D} /(1+\alpha)\right]+(1-\alpha) y_{D}
\end{gathered}
$$

It is thus parameter $\alpha$ that determines the extent to which the household engages in risk diversification across its members and the level of insurance the migrant receives against uncertainty in the destination region. If $\alpha$ equals zero, the migrant is fully exposed to uncertainty in region $\mathrm{D}$ and no risk diversification takes place (which is equivalent to the case of an individual migration decision). If instead, $\alpha$ equals one, migration can reduce the overall

\footnotetext{
${ }^{8}$ Our theoretical framework can be straightforwardly extended to $\mathrm{N}$ household members. In the simulation presented in section VI, we use four household members, reflecting the average household size in our data.
} 
household variance in income, and the migrant and non-migrant members face the same exposure to uncertainty.

\section{B. Household Migration Decision}

The household's decision to send a migrant to the destination region $D$ is made by comparing the household utility of no migration with that of sending one household member to region $D$.

We assume that household members differ only in their degree of risk aversion $k$, have a meanvariance utility function, and jointly maximize the sum of their utilities to act as a coherent unit. $^{9}$

If both members remain in the source region $S$, the household utility is given by

$$
U_{S S}=\left[E\left(y_{S}\right)-k_{1} V\left(y_{S}\right)\right]+\left[E\left(y_{S}\right)-k_{2} V\left(y_{S}\right)\right]=2 \bar{y}_{S}-\left(k_{1}+k_{2}\right) \sigma_{S}^{2}
$$

If instead one household member remains in region $S$ (individual 1) and one migrates to region

D (individual 2), the household utility is given by

$$
\begin{gathered}
U_{S D}=\left[E\left(\tilde{y}^{N M}\right)-k_{1} V\left(\tilde{y}^{N M}\right)\right]+\left[E\left(\tilde{y}^{M}\right)-k_{2} V\left(\tilde{y}^{M}\right)\right]= \\
=\underbrace{\left[\left(\frac{\bar{y}_{\mathrm{S}}+\alpha\left(\bar{y}_{\mathrm{D}}-c\right)}{1+\alpha}\right)-k_{1}\left(\frac{\sigma_{S}^{2}+\alpha^{2} \sigma_{D}^{2}}{(1+\alpha)^{2}}\right)\right]}_{N M}+\underbrace{\left[\left(\frac{\alpha \bar{y}_{\mathrm{S}}+\left(\bar{y}_{\mathrm{D}}-c\right)}{1+\alpha}\right)-k_{2}\left(\frac{\alpha^{2} \sigma_{S}^{2}+\sigma_{D}^{2}}{(1+\alpha)^{2}}\right)\right]}_{M}
\end{gathered}
$$

The household will send a migrant whenever $\mathrm{U}_{\mathrm{SD}}-\mathrm{U}_{\mathrm{SS}}>0$ :

$$
\begin{aligned}
\mathrm{U}_{\mathrm{SD}}- & \mathrm{U}_{\mathrm{SS}}=\underbrace{\left(\frac{\bar{y}_{\mathrm{S}}+\alpha\left(\bar{y}_{\mathrm{D}}-c\right)}{1+\alpha}-\bar{y}_{\mathrm{S}}\right)}_{\Delta E\left(\tilde{y}^{N M}\right)}-k_{1} \underbrace{\left(\frac{\sigma_{S}^{2}+\alpha^{2} \sigma_{D}^{2}}{(1+\alpha)^{2}}-\sigma_{S}^{2}\right)}_{\Delta V\left(\tilde{y}^{N M}\right)}+ \\
& +\underbrace{\left(\frac{\alpha \bar{y}_{\mathrm{S}}+\left(\bar{y}_{\mathrm{D}}-c\right)}{1+\alpha}-\bar{y}_{\mathrm{S}}\right)}_{\Delta E\left(\tilde{y}^{M}\right)}-k_{2} \underbrace{\left(\frac{\alpha^{2} \sigma_{S}^{2}+\sigma_{D}^{2}}{(1+\alpha)^{2}}-\sigma_{S}^{2}\right)}_{\Delta V\left(\tilde{y}^{M}\right)}>0
\end{aligned}
$$

\footnotetext{
${ }^{9}$ The assumption that the family acts as a coherent unit can be justified either (a) based on the existence of a dominant head of household or (b) by a family utility function that is the aggregate of individual utility functions (assuming all household members have the same preferences, including risk aversion) (see Chen et al., 2003). In our case, household members do not have homogenous preferences (i.e. they differ in risk aversion), so we assume that a dominant head of household makes the decision of who migrates on behalf of the household.
} 
These terms thus characterize the change in expected earnings and earnings variance from migration (with respect to non-migration) for both the migrant and the non-migrant household member.

We now identify the conditions under which expression (7) (i.e. the household gains from the migration of one of its members) is positive. ${ }^{10} \mathrm{We}$ first consider the changes in the expected earnings of the non-migrant and migrant, $\Delta E\left(\tilde{y}^{N M}\right)$ and $\Delta E\left(\tilde{y}^{M}\right)$. Both these will be positive as long as the migrant's expected earnings in the destination region (net of migration costs) are larger than in the source region $\left(\bar{y}_{D}-c>\bar{y}_{S}\right)$. We then consider the changes in the earnings variances for the non-migrant and the potential migrant, $\Delta V\left(\tilde{y}^{N M}\right)$ and $\Delta V\left(\tilde{y}^{M}\right)$. Figure 1 shows the relation between $\sigma_{D}^{2}$ (horizontal axis) and the change in earnings variance (vertical axis) for the migrant $\left(\Delta V\left(\tilde{y}^{M}\right)\right)$ and non-migrant $\left(\Delta V\left(\tilde{y}^{N M}\right)\right)$. Although both changes in variance are increasing functions of $\sigma_{D}^{2}, \Delta V\left(\tilde{y}^{M}\right)$ is steeper than $\Delta V\left(\tilde{y}^{N M}\right)$, with slopes of $1 /(1+\alpha)^{2}$ and $\alpha^{2} /(1+\alpha)^{2}$, respectively. This reflects the higher exposure of the migrant to risk in the destination region. ${ }^{11}$ According to Figure 1, the intersection of these two lines with each other and with the zero line creates three different scenarios for $\sigma_{D}^{2}>\sigma_{S}^{2} \cdot{ }^{12}$ To the right of the two-line intersection but before either line intersects the $x$-axis $\left(\sigma_{D}^{2}<(1+2 \alpha) \sigma_{S}^{2}\right.$; area I), $\sigma_{D}^{2}$ is only moderately larger than $\sigma_{S}^{2}$, so risk diversification leads to a decrease in earnings risk for both migrant and non-migrant $\left(\Delta V\left(\tilde{y}^{M}\right)\right.$ and $\Delta V\left(\tilde{y}^{N M}\right)$ are both negative). For intermediate values of $\sigma_{D}^{2}\left((1+2 \alpha) \sigma_{S}^{2} \leq \sigma_{D}^{2}<\frac{2+\alpha}{\alpha} \sigma_{S}^{2}\right.$; area II) earnings risk decreases for the non-migrant

\footnotetext{
${ }^{10}$ We do not consider migration of entire households because the risk diversification motive would not apply any longer. As discussed in the previous section, in the context we empirically analyse entire households do not usually emigrate.

${ }^{11}$ The difference in the slope of the two lines is inversely related to the parameter $\alpha$, which determines the degree of income pooling: when income pooling is perfect $(\alpha=1)$ the two lines overlap.

${ }^{12} \mathrm{~A}$ fourth case (area 0 in the graph) arises whenever $\sigma_{D}^{2}<\sigma_{S}^{2}$. In this scenario, not only does the earnings risk decrease for both migrant and non-migrant, but also the earnings risk of the migrant is lower than that of the nonmigrant.
} 
but increases for the migrant. Finally, for high values of $\sigma_{D}^{2},\left(\sigma_{D}^{2} \geq \frac{2+\alpha}{\alpha} \sigma_{S}^{2}\right.$; area III), migration increases earnings risk for both household members.

The actual decision to migrate, however, also takes into account the relative gains in expected earnings. Note that in this model, risk diversification alone may lead the household to choose to send a migrant, even if the earnings differential between source and destination regions is zero. In the case of a zero earnings differential (net of migration cost) between source and destination region, indeed, migration will always be optimal in area I (in which both individuals reduce their exposure to risk by having one migrant in the household). There will be migration in area II as long as the utility gain in reducing uncertainty of the non-migrant member more than compensates for the loss experienced by the migrant. Finally, no migration will take place in area III. Positive earning differentials, however, may shift these decisions, meaning that migration may also take place in area III.

\section{Who Will Emigrate?}

We now investigate the household's choice of whom of its members to send as a migrant. We first note that if the earnings variance is higher in the destination region than in the source region $\left(\sigma_{\mathrm{D}}^{2} \geq \sigma_{\mathrm{S}}^{2}\right)$, the migrant is always exposed to at least as high an income variance as the non-migrant (for any value of $0 \leq \alpha \leq 1$ ):

$$
V\left[\tilde{y}^{M}\right]=\left(\frac{\alpha^{2} \sigma_{S}^{2}+\sigma_{D}^{2}}{(1+\alpha)^{2}}\right) \geq V\left[\tilde{y}^{N M}\right]=\left(\frac{\sigma_{S}^{2}+\alpha^{2} \sigma_{D}^{2}}{(1+\alpha)^{2}}\right) \quad \text { if } \quad \sigma_{\mathrm{D}}^{2} \geq \sigma_{\mathrm{S}}^{2}
$$

The decision of which of the two individuals will emigrate will be based on the comparison of household utility when one member, rather than the other, migrates. We have:

Proposition 1. As long as migration is riskier than non-migration, $V\left[\tilde{y}^{M}\right] \geq V\left[\tilde{y}^{N M}\right]$, it is always optimal to choose the least risk averse individual in the household as the potential 
migrant (although it may be optimal to send nobody). If instead $V\left[\tilde{y}^{M}\right] \leq V\left[\tilde{y}^{N M}\right]$, it is optimal to choose the most risk averse individual in the household.

Proof. See Appendix A.I.A

While if the migration decision is made at the individual level (which corresponds to the case where $\alpha=0$ ), only own risk tolerance should matter, proposition 1 implies that at the household level, the elasticity of migration probabilities to individual risk aversion depends also on the way individuals with different risk attitudes mix within the household. Hence, the risk aversion of individuals relative to the risk aversion of other household members should also matter. In other words, whereas two individuals with identical risk aversion would, all else being equal, have the same probability of migrating in an individual migration decision model, in a household decision model, that probability will differ depending on the composition of the risk aversion of the other household members.

Empirically, an individual decision model would predict a lower average risk aversion among the migrant population than among the non-migrant one when income variance at destination is higher than in the source region. This prediction is also compatible with the household migration decision model outlined above. However, whereas the individual model makes no predictions about how the migration probability relates to the risk aversion of other household members, the household decision model predicts that the relative position in the within household risk tolerance ranking - and not just the individual risk tolerance - matters for the migration probability. This is one of the implications of the model that we will test below.

\section{Which household will send a migrant?}

Which households, then, are more likely to send migrants? The answer involves two counteracting factors within each household. On the one hand, migration can reduce the income uncertainty of the non-migrant household members, and their utility gain increases with their 
risk aversion. On the other hand, if migrating involves more exposure to uncertainty, the household needs members with sufficiently low risk aversion as suitable candidates for migration. Hence, in a household in which everyone is very risk averse, although there is a strong desire for risk diversification, no member will be a good candidate for migration. Conversely, in households in which all members have low risk aversion, there will be many candidates for migration but lower demand for risk diversification. Thus, the likelihood of a household sending a migrant will depend on the distribution of risk attitudes within the household. We formalize this intuition in the following proposition:

\section{Proposition 2}

(i) Consider two households that differ only in the risk aversion of their members but have identical average risk aversion. If migration increases (reduces) the exposure to risk of the migrant member, the household with more (less) variation in its members' risk preferences will benefit the most from migration.

(ii) Consider two households that differ only in the degree of risk aversion of the least risk averse individual. If migration increases (reduces) the exposure to risk of the migrant member, the household whose least risk averse individual has lower (higher) risk aversion will benefit the most from migration. [Alternatively: Consider two households that differ only in the degree of risk aversion of the most risk averse individual. If migration reduces (increases) the exposure to risk of the non-migrant member, the household whose most risk averse individual has higher (lower) risk aversion will benefit the most from migration.]

Proof. See Appendix A.I.B.

According to proposition 2, when migration is risky households are more likely to send migrants if they have some members with low risk aversion (who are good candidates for migration) and some with high risk aversion (who will gain most by sending another household 
member to reduce their exposure to income uncertainty). This observation implies that, beyond the risk aversion of individual members, the within household dispersion in risk aversion affects the likelihood that a household sends a migrant. Again, this is an implication tested below.

\section{Data and Descriptives}

\section{A. The RUMiC Survey}

Our primary data source is the Rural Household Survey (RHS) from the Rural-Urban Migration in China (RUMiC) project (henceforth RUMiC-RHS). RUMiC began in 2008 and it conducts yearly longitudinal surveys of rural, urban, and migrant households. The RUMiC-RHS was

conducted for 4 years and administered by China's National Bureau of Statistics. It covers 82 counties (around 800 villages) in 9 provinces identified as either major migrant sending or receiving regions and is representative of the populations of these regions. The survey includes a rich set of individual and household level variables that contains not only the usual demographic, labour market, and educational data but also information on individual migration experience and subjective rating of willingness to take risks, both particularly relevant to this study. Unlike other surveys, it records information on all household members whose hukou are registered in the household. Thus, household members who were migrated to cities at the time of the survey were also included. Information on household members who were not present at the time of the survey was provided by the main respondent, however, questions related to subjective issues and opinions (e.g. risk attitudes) are only answered by individuals who were present at the time of the survey. In this paper, we use data from the 2009 RUMiC-RHS, conducted between March and June of that year, which was the first wave that reports information on risk aversion. 
To identify migrants, the survey includes questions on the number of months each individual spent living away from home during the previous year (i.e. 2008) and the reason for their absence (e.g. education, military service, work/business, visiting friends and relatives.) We thus define a labour migrant as an individual who spent 3 or more months away from home in the previous year for work or business purposes. In the 2009 wave of the RUMiC-RHS survey interviewees were asked to rate their attitudes towards risk. The question states "In general, some people like to take risks, while others wish to avoid risk. If we rank people's willingness to take risks from 0 to 10 , where 0 indicates 'never take risk' and 10 equals 'like to take risk very much,' which level do you think you belong to?" According to a recent literature, responses to direct questions on self-reported risk aversion are reasonable proxies of more objective measures of risk attitudes obtained from having respondents playing lotteries (Ding, Hartog, \& Sun, 2010; Dohmen et al., 2011). Moreover, Frijters, Kong, and Meng (2011) have specifically validated the risk attitude question used in the RUMiC survey. ${ }^{13}$

In our empirical analysis, we test the predictions of the theoretical model presented in section III by investigating individual as well as household migration probabilities (see section V). For the individual level analysis we focus on individuals who are in the workforce and who, therefore, are potential migrants. The 2009 RUMiC-RHS survey includes 17,658 individuals in the labour force (i.e. aged between 16 and 60 and not currently at school or disabled) who provide information about age, gender, educational level and migration status. ${ }^{14}$ To be able to carry out our analysis we restrict the sample to individuals living in households where at least two members in the work force have reported risk preference, which reduces the sample to 7,808 individuals. As Panel A in Appendix Table A1 shows, the sample of individuals in

\footnotetext{
${ }^{13}$ Frijters, Kong, and Meng (2011) ask a random sub-sample of 1,633 rural-urban migrants from the Urban Survey to play a risk game similar to that used by Dohmen et al. (2011). They find that self-assessed risk and the risk measures revealed by the game are highly correlated, with a correlation coefficient of 0.7 .

${ }^{14}$ The 2009 RUMiC-RHS survey includes a total of 32,249 individuals. We focus on those aged $16-60$ because the probability of being a migrant drops below $1 \%$ for individuals over 60 . Nevertheless, shifting the upper bound of this age range by five years (in either direction) does not alter our empirical findings.
} 
households we focus on is almost identical in observables to that of individuals in households in the overall sample. Information on risk aversion is available for $81 \%$ of such sample, leading to a final estimating sample of 6,332 individuals. For the household-level analysis, we use all households where at least two members reported their willingness to take risks, but we also include individuals above age 60, as their risk aversion is likely to matter for decisions of the household whether or not to send a migrant, which results in a sample of 2961 households. ${ }^{15}$ Panel B in Table A1 shows that these households are almost identical in observable characteristics to the overall sample.

The risk attitudes question can only be answered by respondents who are present at the time of the survey, which is a potential problem for migrants. In our data, the share of non-responses is higher among migrants (55\%) than among non-migrants (10\%). ${ }^{16}$ This may be problematic if unobservables that affect the probability to be present at the time of the interview are correlated with individual risk aversion, conditional on observables. There is no reason to believe that migrants who happened to be present at home between March and June in 2009 differ systematically in risk attitudes from migrants who were absent. To nevertheless test this hypothesis, we make use of the fact that we observe individual characteristics also for those who are absent at the time of the survey as these are reported by other family members; as discussed above, attitudes towards risk is the only missing information in such cases. We estimate a simple selection model using family events such as death, marriage, or birth that occurred before or after the interview as instruments to identify the participation equation, i.e. whether the migrant was present at the interview. These events, while arguably uncorrelated

\footnotetext{
${ }^{15}$ Excluding individuals over 60 from the household sample lead to very similar estimation results.

${ }^{16}$ In comparison with similar surveys in other developing countries, the RUMiC-RHS survey has a much higher response rate for migrants, due to the special institutional settings of internal migration in China. As discussed earlier, most migrants are still subject to a rural hukou in their home village and leave their immediate family behind to go and work in cities. To look after their left-behind relatives, repeated short term migration spells are common. Moreover, the majority of migrants return home for the Chinese New Year (or Spring Festival), celebrated between late January and early February, and stay on for some weeks or months. All this increases the chances of finding migrants in their home village at the time of the survey.
} 
with migrants' risk attitudes, may have induced the individual to return to the home village, or to remain longer at home, and hence increased the probability of participating in the survey. We then construct the generalised residuals and include them in an equation where willingness to take risk is the dependent variable, conditioning in both equations on other observables that are used in the main analysis. A test of correlation between the unobservables determining survey participation and individual risk attitudes corresponds then to a simple t-test of whether the coefficient of the generalised residual is significantly different from zero (see Wooldridge, 2002). Despite our instruments being strong predictors for interview participation, we cannot reject the null hypothesis that the residual correlation in risk aversion and interview participation is zero for any of the specifications we estimate. We provide details of this test in appendix A.II, and report estimates in Table A 2.

\section{B. Descriptive Statistics}

We provide descriptive statistics on individual characteristics in the upper panel of Table 1. The numbers show that males account for about half our sample, with an average age of 43.8 years and an average education of 7.15 years. About $92 \%$ of our respondents are married and have on average 3.1 siblings and 1.7 children. The average of our measure of willingness to take risks is 2.6 (with a standard deviation of 2.4). The lower panel of Table 1 shows the characteristics of the 2,961 households in our sample. The average household size is 4.1 , with an average of 2.9 individuals of working age. ${ }^{17}$ About $16 \%$ of the households in the sample have at least one member who migrated in the previous year, and $11 \%$ of the individuals in our sample can be classified as migrants, with the rate among males and females being $14.0 \%$ and $7.9 \%$, respectively. Further, about $23 \%$ of the interviewees in our sample reported having

\footnotetext{
${ }^{17}$ The one-child policy introduced in 1979 was less restrictive in rural areas (allowing rural families to have a second child if the first one was a girl) and less strictly enforced. In our sample, individuals born before and after 1979 have an average of 3.3 and 2.1 siblings, respectively.
} 
migrated at least once in the past. In our empirical analysis, we will use this as a second measure for migration status to check the robustness of our findings.

The distribution by migrant status of our measure of willingness to take risk, which ranges between 0 (highest level or risk aversion) and 10 (lowest risk aversion), is plotted in Figure 2. For both groups of respondents, the distribution is skewed to the left: the mode value is zero for both migrants and non-migrants, and the share of respondents categorizing themselves as being at the highest level of risk aversion is $18 \%$ and $31 \%$, respectively. The unconditional mean of the measure is 2.4 and 3.6 for non-migrant and migrants, respectively. Hence, the migrant distribution is clearly shifted more towards less risk aversion than the non-migrant distribution.

To illustrate the relation between household and individual risk aversion, we compute the residuals from regressing individual willingness to take risks on basic demographic controls (gender, age, and age squared) and a full set of county of residence dummies. Figure 3 plots the residuals for each individual in our sample (on the vertical axis) versus the average residual of other household members (on the horizontal axis). The fitted line shows a clearly positive relation between individual and household residual risk attitudes (with a correlation of about 0.58), which confirms Dohmen et al.'s (2012) findings on German households. ${ }^{18}$ On the other hand, the scatter plot also shows considerable variation, a within household heterogeneity we exploit in our regression analysis (see section V). ${ }^{19}$

\section{Empirical Strategy and Results}

In our empirical analysis, we address two issues. First, how risk aversion determines individual migration decisions. Second, the role of risk attitudes at the household level for migration

\footnotetext{
${ }^{18}$ Using GSOEP data, Dohmen et al. (2012) show evidence of within-household correlation in preferences towards risk. They argue that intergenerational transmission of risk attitudes and assortative mating of parents may generate this observed correlation.

${ }^{19}$ This is in line with evidence provided by Mazzocco (2004) of imperfect assortative mating on risk aversion in US couples. Using data from the Health and Retirement Study (HRS), he shows that self-reported risk attitudes differ between husband and wife for about 50 percent of the couples in the sample.
} 
decisions. In this second part, we first investigate whether and to what extent relative risk preferences among individuals within the family determines who among them should migrate (within household migration decision). We then examine which households are more likely to send migrants (across household migration decision).

\section{A. Individual Migration Decisions}

To assess this first aspect, we estimate the following equation:

$$
\operatorname{Pr}\left(M_{i h k}=1\right)=\alpha_{0}+\alpha_{1} w t \text { Risk }_{i h k}+\mathbf{X}^{\prime}{ }_{i h k} \beta+\mathbf{W}_{h k}^{\prime} \theta+\eta_{k}+\epsilon_{i h k}
$$

where $i$ indexes individuals, $h$ households, and $k$ administrative counties. The variable $M_{i h k}$ is an indicator of whether individuals have spent at least 3 months working outside their origin area during the previous year. Our main variable of interest is the willingness to take risks, $w t$ Risk $_{i h k}$, measured on a scale from 0 (lowest risk tolerance) to 10 (highest risk tolerance). The vector $\mathbf{X}^{\prime}{ }_{i h k}$ collects a set of individual-level covariates that are important determinants of the individual migration probability, including gender, age, age squared, marital status, number of children, years of education, number of siblings, birth order and the relation with the head of household. The vector $\mathbf{W}_{h k}^{\prime}$ includes a set of family characteristics, such as household size and structure (number of family members under 16, in the work force, or older than 60); and per capita house value (in logs). We also include county fixed effects $\eta_{k}$ to capture any time invariant observable and unobservable area characteristic that may be correlated with both attitude towards risk and propensity to migrate. ${ }^{20}$ An individual or household migration decision model in which migration implies exposure to higher uncertainty would imply that migrants are more risk tolerant than non-migrants. We thus expect the coefficient $\alpha_{1}$ in equation (9) to be positive.

\footnotetext{
${ }^{20}$ Dohmen et al. (2012) provide evidence of correlation in risk aversion among individuals residing in the same area.
} 


\section{A.1 Main results}

Table 2 summarizes the results from our estimation of a linear probability model of equation (9). ${ }^{21}$ We use two alternative measures of migration status: whether the individual migrated for work during the year before the survey (columns 1-5) and whether the individual had ever migrated in the past (columns 6-10). In all regressions, we include a full set of 82 county dummies and cluster the standard errors at the household level to allow for within household correlation in the error terms. In column 1, we report the results of regressing individual migration status on our measure of willingness to take risk, after which we successively add in further individual and household controls (columns 2-4). All estimates show a strong positive association between individual risk tolerance and the probability of being a migrant, which suggests that individual risk attitudes play an important role in determining individual propensities to migrate. The estimated coefficient on the $w t R i s k$ variable reduces in magnitude when basic individual controls are included (from 0.014 in column 1 to 0.005 in column 2), but remains stable when additional individual controls and household characteristics are added in (columns 3-4). This pattern is consistent with basic demographic characteristics such as gender and age being strong predictors of individual risk attitudes (see among others, Barsky et al. 1997 and Borghans et al. 2009). The effect estimated is economically relevant: in our most restrictive specification (column 4), a one standard deviation increase in the willingness to take risks is associated with a 1.2 percentage point increase in the migration probability, corresponding to an $11 \%$ increase with respect to the baseline migration probability of $11 \%$. This positive relationship between willingness to take risks and probability of migration is consistent with internal migration in China exposing migrants to higher level of uncertainty than non-migrants.

\footnotetext{
${ }^{21}$ The marginal effects based on probit or logit estimators, reported in Appendix Table A2, are almost identical to those reported here.
} 
In columns 6-10 of Table 2, we report estimates for the alternative migration status measure of whether individuals have ever migrated for work. About $23 \%$ of the interviewees in our sample reported having migrated at least once in the past. As before, willingness to take risk is a strong predictor of migration status: in the most general specification (column 8), a decrease of one standard deviation in the willingness to take risk is associated with a 3.3 percentage points increase in migration probability, corresponding to about $14 \%$ of the baseline sample probability, an estimate that is very close to the one obtained with migration in year 2008 as the main outcome. ${ }^{22}$

In column 5 and 10 of Table 2, we investigate gender heterogeneity in the relations between risk tolerance and migration probability by interacting the $w t R i s k_{i h k}$ variable with a male and a female dummy: in both cases, the estimated coefficients are very similar for the two genders. We further analyse the linearity in the relation between migration propensity and risk attitudes and we estimate equation (9) with a set of five dummies for different levels of willingness to take risks (the excluded dummy corresponds to a zero willingness to take risks). Panels A and B of Figure 4 report the estimated coefficients and their $90 \%$ confidence intervals for the two measures of migration based on the specification in columns 4 and 9 of Table 2 . The figure shows a clear and almost linear relation between migration probability and individual willingness to take risks above values of about 2 .

These findings on individual migration decisions are much in line with previous findings in the literature. For instance, while a one standard deviation increase in risk tolerance leads to an $11 \%$ or $14 \%$ increase, respectively, in the baseline probability of having migrated in the previous year or overall, Jaeger et al. (2010), using a specification almost identical to that

\footnotetext{
${ }^{22}$ In Appendix Table A4, we report estimated coefficients on the other controls. As expected, male, non-married and younger individuals are more likely to migrate, while education does not seem to predict migration status (see column 4).
} 
reported in column 2 of Table 2, report that a one standard deviation increase in risk tolerance leads to a $12 \%$ increase in the baseline migration probability.

\section{A.2 Robustness checks}

Although our regressions condition on a large set of individual and household controls, one may still worry that selection into migration is driven by unobservable urban wage determinants that are also correlated with individual risk attitudes. As a robustness check, we further condition on several physical and health characteristics that are likely to affect the migrants' productivity in the manual jobs they usually hold in cities. As Appendix Table A5 shows, the inclusion of height, weight and a set of dummies for (self-reported) health status does not change our estimates of the coefficient on the willingness to take risk.

A second possible concern with our results is that, because attitudes towards risk are measured after the migration decision, the migration experience itself may have affected the risk attitudes reported during the interviews. A growing empirical and experimental literature has investigated the stability of risk preferences that are generally assumed to be constant over time in economic models. Chuang and Schechter (2015) review this evidence and show that even in the case of extreme negative events (e.g. natural disasters, war and violence) the literature has produced contradictory results on whether risk preferences react to shocks. Clear evidence supporting the stability of risk attitudes is instead found for less dramatic events, such as changes in income (Brunnermeier and Nagel, 2008). As far as migration is concerned, Jaeger et al. (2010) find that internal migration in Germany does not affect risk tolerance of individuals. Similarly, Gibson et al. (2016) show that having migrated internationally (from Tonga to New Zealand) produces no significant impact on risk (and time) preferences, even if it implies a dramatic increase in lifetime earnings and the exposure to a profoundly different economic and social environment. 
We can investigate the stability of risk attitudes of respondents in our sample by exploiting the longitudinal nature of the survey. Almost half of our estimation sample reported risk attitudes in both the 2009 and the 2011 waves of the RUMiC-RHS. The Appendix Figure A2 reports the distribution of changes in self-reported risk attitudes between 2009 and 2011 and suggests that interviewees report their risk preferences fairly consistently over time. ${ }^{23}$

Further, we test whether migration experiences are systematically related to changes in risk aversion by regressing the change in self-reported willingness to take risks between 2009 and 2011 on a dummy variable indicating migration status in year 2010. This test is analogous to the one carried out in Jaeger et. al. (2010). We report results in Panel A (columns 1-4) of Appendix Table A6. Alternatively, we regress the willingness to take risks reported in 2011 on a dummy for migration in 2010 while controlling for the willingness to take risks reported in 2009 (Panel A, columns 5-8). According to the estimation results, having migrated in 2010 does not affect the observed change in risk preferences or the level of risk preferences in 2011 when controlling for risk attitudes in 2009. In all specifications, estimated coefficients are not significant and of small magnitude. In Panel B of Table A6 we report the same regressions than in Panel A, but we distinguish between individuals who were migrants only in 2010 and individuals who were migrants in both 2008 and 2010. Again, estimates are very small for both measures, and not significantly different from zero throughout.

Finally, to rule out any remaining concern about reverse causality, we restrict our sample to individuals who migrated for the first time in 2009,2010 or 2011, i.e. after risk aversion was measured. We then investigate whether their willingness to take risk predicts future migration decision. Because the incidence of first-time migrants on the population declines sharply with

\footnotetext{
${ }^{23}$ In our sample, the average change in willingness to take risks between 2009 and 2011 is relatively small, 0.39 for a measure ranging between 0 and 10 . About one fourth of the respondents reported exactly the same value in both surveys, while almost half reported changes smaller than or equal to plus or minus one, and about $80 \%$ showing changes ranging between 0 and 3 . On average, the change in self-reported willingness to take risks over two consecutive waves (2009 and 2010) is 0.2 and almost 40 percent of the sample reports identical risk preferences.
} 
age, we focus on individuals aged between 16 and 36 years old, although results are similar for the entire sample. Appendix Table A7 shows that willingness to take risks (measured in early 2009) is positively associated with the probability that the individual will migrate for the first time later in 2009, 2010 or 2011 (columns 1-4). Coefficients are significant and very similar in magnitude (if anything larger) to those obtained in our main estimates (see Table 2). ${ }^{24}$

\section{B. Within Household Migration Decision}

Establishing that individual risk tolerance determines migration choices is compatible not only with a model of individual choice but also with a model in which migration decisions are taken at the household level. If such decisions are taken on a purely individual level, however, the risk attitudes of other household members should play no role in determining migration decisions. Proposition 1 of our theoretical model, instead, implies that the individual probability of being a migrant should depend on both the individual's own risk aversion and the risk preferences of other household members (section III.C). We test this proposition in three ways.

In our first approach, we still run individual-level regressions but now explicitly include both the individual's risk preferences (wtRisk) and the individual's position in the household ranking of risk tolerance (wtRisk_rel) among members in the work force. The coefficient on this latter variable is identified from individuals who have the same level of risk tolerance (wtRisk) but who hold different positions in the risk tolerance ranking within their respective households. According to proposition 1, when migration is risky, all else being equal, the most risk tolerant individuals in the household should have a higher probability of migrating. The

\footnotetext{
${ }^{24}$ To further investigate a possible relation between our measure of risk aversion and migration experience, we use data from various waves of the Urban Migrant Survey (UMS) of the RUMiC project and test whether risk preferences vary across migrations of different duration. In particular, we regress risk attitudes of migrants on the years since first migration, while controlling for individual characteristics as well as for city and year fixed effects. We report estimates in Appendix Table A8, where columns 1 and 2 report results unconditional and conditional on individual fixed effects, respectively. Estimated coefficients of migration duration are very small in magnitude and never significantly different from zero.
} 
ordinal measure of risk preferences (wtRisk_rel) should thus have an effect over and above the effect of the cardinal measure (wtRisk). In the regressions presented in Table 3, we use two alternative measures for the individual's ranking wtRisk_rel. First, we define the individual position in risk attitudes within the household by ranking household members according to their willingness to take risks. We then assign a value of 1 to the least risk tolerant, and a value of $n$ to the most risk tolerant individual (where " $n$ " is the number of household members in the work force reporting risk preferences), and we then normalize this measure by $n{ }^{25}$ The second measure is a dummy variable that takes value one if the individuals have the highest risk tolerance in their households and zero otherwise. ${ }^{26}$ Both these variables increase with the focal individual's willingness to take risks. If, as proposition 1 suggests, being relatively more willing to take risks with respect to the other household members makes individuals more likely to migrate, then we would expect positive coefficients for both the level and the relative risk tolerance variables.

We report estimation results in Table 3 for our preferred specification that includes county fixed effects as well as individual and household controls, and clusters standard errors at the household level. For comparative purposes, column 1 of Table 3 replicates column 4 of Table 2. In columns $2-5$, we add our two alternative measures of relative risk attitudes, where we include only the relative measure for each variable in even columns and both the relative and absolute willingness to take risks in odd columns. Consistent with our theoretical predictions, the estimated coefficients are positive and significant for all relative measures of willingness

\footnotetext{
${ }^{25}$ For example in a household with 4 members, the most risk tolerant would be assigned a value of $4 / 4$ (1) and the least risk tolerant a value of $1 / 4$. The other two individuals would get $3 / 4$ and $2 / 4$ respectively.

${ }^{26}$ In constructing these variables, we need to decide how to treat cases in which some household members reported identical values of risk attitudes. For the ranking measure, we assign an average ranking to individuals with the same willingness to take risks (e.g. if two individuals are ranked second in the household, we assign a ranking of 2.5 to each and a ranking of 4 to the next household member, if any). In our second procedure, we assign the value 1 if the individual has the lowest risk aversion in the household, irrespective of other household members possibly reporting the same level of willingness to take risks. We have experimented with alternative methods for dealing with ties in other unreported regressions, but our empirical results do not change. These estimates are available upon request.
} 
to take risks. This finding also holds when we include both absolute and relative risk tolerance (columns 3 and 5): the estimated coefficients are positive and significant on both variables, implying that the relative measure of risk attitudes affects the probability of migrating over and above the individual's risk preference. As a result, not only are individuals with low risk aversion more likely to migrate, but this probability increases for those who are relatively less risk averse than their family members. Specifically, according to the estimates in column 5, being the most risk tolerant in the household implies a 1.4 percentage point higher likelihood of migrating (around 13\% of baseline) than for an individual with the same individual risk attitude who is not the least risk averse in the household.

Our second approach is to re-estimate equation (9) including both individual risk attitudes $\left(w t R i s k_{i h k}\right)$ and the average risk tolerance of the other household members who are in the workforce $\left(w t R i s k \_o t h_{i h k}\right)$. Conditional on their own risk attitudes, individuals who belong to a household in which the other members are relatively less willing to take risks (i.e. have lower values of the wtRisk_oth variable) should be more likely to migrate. Following the structure of the previous columns in Table 3, in column 6 we include the wtRisk_oth variable alone, while both variables are included in column 7 . We expect this latter variable to have no predictive power alone, but, conditional on individuals' own risk tolerance, a higher risk tolerance among other household members should reduce individual probability of being a migrant. We thus expect to find a positive coefficient on the wtRisk variable (as in all previous regressions) and a negative coefficient on the wtRisk_oth measure. Both hypotheses are supported by the data: the estimated coefficient on wtRisk_oth is zero (column 6) but becomes significant and negative once we condition on individual willingness to take risks (column 7). As in all previous regressions, the coefficient on this latter variable is positive and significant. In our third, and final, approach we regress the individual migration probability on the wtRisk variable - or, alternatively, on an indicator for being the least risk averse in the household - 
and include household fixed effects in order to explicitly condition on all unobservable characteristics common to all household members, including average risk preferences. Our estimates (see Appendix Table A9) show that individuals with values of willingness to take risks above the household average are significantly more likely to migrate, confirming previous results.

An important implication of our analysis so far is that migration decisions in the context that we study are taken on the level of the household rather than the single individual. Our results further provide strong evidence of the within-household migration decision being consistent with a model, where beyond individual willingness to take risks, risk preferences of other household members matter, with the direction of the effects being in line with our Proposition 1.

\section{Across Household Migration Decision}

We assess next which households have a higher probability of sending migrants and test statements (i) and (ii) of proposition 2 (see section III.D), by estimating household-level regressions of the probability of sending a migrant. The first statement suggests that, conditional on having the same mean risk tolerance, households with a larger variation in risk preferences should be more likely to send migrants. We test this prediction by estimating the following equation:

$\operatorname{Pr}\left(M_{h k}=1\right)=\delta_{0}+\delta_{1} H H_{-}$avg_wtRisk ${ }_{h k}+\delta_{2} H H_{-}$range_wtRisk $k_{h k}+\mathbf{W}_{h k}^{\prime} \theta+\eta_{k}+u_{h k}$

where the probability that a household sends a migrant depends on the average risk aversion in the household ( HH_avg_wtRisk), the within-household range in risk attitudes (HH_range_wtRisk), other household controls and county fixed effects. ${ }^{27}$ Conditional on

\footnotetext{
${ }^{27}$ We define the within household range as the difference between the highest and lowest values of willingness to take risks reported in each household. The household controls are number of family members under 16 , in the
} 
household average risk aversion, we expect households with a larger variance in risk attitudes to be more likely to send a migrant. Estimation results are reported in Table 4 . When the regression includes only the household's average risk tolerance (columns 1 and 3), the coefficient is positive and strongly significant: households that are on average more risk tolerant are more likely to engage in migration. As correlation in risk attitudes within households is sizeable in our sample (see section IV.B), this finding may simply reflect that more risk tolerant individuals are more likely to migrate and at the same time, belong to households whose members are also more risk tolerant. Hence, in columns 2 and 4 of Table 4 , we add in the within household range in risk attitudes. These estimates indicate that, in line with our theoretical model, households with a higher variation in risk preference across members are more likely to send migrants conditional on the average household risk aversion. In both specifications, only the range, and not the mean, of household risk preferences is significantly (and positively) associated with having sent a migrant.

The second statement in proposition 2 implies that (if migration implies exposure to higher uncertainty) the probability of a household sending a migrant increases with the willingness to take risk of the most risk tolerant member, the best candidate for migration according to our model, but simultaneously decreases with the willingness to take risk of the other (non-migrant) members who would achieve income diversification with migration. To test this implication, we estimate the following household-level equation:

$$
\begin{gathered}
\operatorname{Pr}\left(M_{h k}=1\right)=\gamma_{0}+\gamma_{1} H H_{-} \text {max }_{-} w t R i s k_{h k}+\gamma_{2} H H_{-} o t h \_w t R i s k_{h k}+\mathbf{W}_{h k}^{\prime} \theta+\eta_{k}+ \\
u_{h k}(11)
\end{gathered}
$$

where we separately include in the regression the risk preferences of the most risk tolerant individual in the household (HH_max_wtRisk) and the average risk tolerance among the other

work force, and older than 60; per capita house value; size of the family plot; and years of education and age of the head of the household. 
household members (HH_oth_wtRisk). Our theoretical framework would lead us to expect the coefficients on these two risk measures to have opposite signs. Table 5 reports our estimates of equation (11). All regressions include county fixed effects, and household controls are added in columns 3, 4 and 6 . When only the willingness to take risks of the most risk tolerant individual in the household $\left(H H_{-}\right.$max $\left._{-} w t R i s k_{h k}\right)$ is included in the regression (columns 1 and 3), we find a positive and strongly significant coefficient. This coefficient remains positive and significant (slightly increasing) when the specification also includes the average risk tolerance of the other household members ( $H_{H} \_$oth_wtRisk $k_{h k}$ ), whereas the coefficient on HH_oth_wtRisk is negative (columns 2 and 4). ${ }^{28}$ Results suggests that, in line with our model's predictions, the probability of sending a migrant is higher for the household in which the most risk tolerant individual has a higher willingness to take risks (high value of $H H_{-}$max_wtRisk $\left.k_{h k}\right)$. At the same time, the probability of sending a migrant is higher for households in which the average risk tolerance among other individuals in the household is lower (low value of $H H_{-}$oth_wtRisk), keeping risk tolerance of the least risk averse member constant. Thus, our results are in line with a scenario in which migration increases exposure to risk for the migrant member while reducing income risk for the non-migrant ones.

Finally, in column 5 and 6 of Table 5, we check the robustness of our findings to changes in the age limit for individuals to be considered part of the workforce by reducing it from 60 to 50 years. Our estimates remain unaffected, becoming if anything more significant in spite of a $25 \%$ reduction in sample size.

Hence, in line with the predictions of our theoretical model, a household has a higher probability to send a migrant the higher the willingness to take risks of the most risk tolerant member and the less risk tolerant the other household members are. The estimates in column

\footnotetext{
${ }^{28}$ The increase in the size of the coefficient on $H H_{-}$max_wtRisk when conditioning on HH_oth_wtRisk is compatible with $H_{H_{-}}$oth_wtRisk having a negative effect on the migration probability and being positively correlated with $H H_{-}$max_wtRisk.
} 
4, specifically, suggest that a one unit decrease in the measure of willingness to take risks of the least risk averse household member implies a 1.5 percentage point increase in the household's probability of sending a migrant, corresponding to a $9 \%$ increase over the baseline household migration probability (see Table 1). At the same time, a one unit increase in the average risk aversion among all other household members, conditional on the most risk tolerant member's risk attitudes, is associated with a 0.8 percentage points increase in the household's probability of sending a migrant (or a 5\% increase), although the coefficient is not precisely estimated. ${ }^{29}$

The findings in Table 5, combined with the other estimates in Table 4, suggest that the distribution of risk attitudes within the household plays an important role in the household's decision to send a migrant. In particular, households with a high demand for risk diversification but at the same time with at least one individual risk tolerant enough are those benefitting more from sending a migrant. The direction of the estimated effect is consistent with the predictions of our theoretical framework.

\section{An Illustration of Individual and Household Decisions}

Our empirical analysis provides strong evidence that, in the context of rural China, migration decisions are taken at the household level and that heterogeneity in risk aversion within the household plays an important part in shaping these decisions. In this section, we conduct simulations to examine the implications of an individual versus a household decision model for migration rates and for the selection of migrants and non-migrants according to their risk aversion. We generate a population of 10,000 individuals with mean-variance utility functions that are randomly assigned a value of willingness to take risks (varying between zero and ten),

\footnotetext{
${ }^{29}$ Approximately $40 \%$ of the households with migrant members have more than one migrant. In Appendix Table A10, we replicate our estimates in Table 4 and 5 using as outcome in the regressions the share of migrant household members rather than the probability of having a migrant member. All our results are robust to this alternative definition of the dependent variable.
} 
and whose distribution mimics the one we observe in our data. Further, we set expected earnings in the source region equal to 5000 yuan (with a standard deviation of 3000) and expected earnings in destination region $D$ as twice as large as in region $S$ (see section II). ${ }^{30} \mathrm{We}$ then let the earnings variance at destination $V\left(y_{D}\right)$ vary in the interval $\left[0.1 * V\left(y_{D}\right) \leq\right.$ $\left.V\left(y_{S}\right) \leq 4 * V\left(y_{D}\right)\right]$ to study how migration choices react to relative changes in the earnings variance in the two regions.

We simulate migration decisions under an individual and a household model. In the individual model, there is no income pooling $(\alpha=0)$ and each agent autonomously decides whether it is optimal to migrate or not. All agents face the same expected income and income variance but differ in migration costs. ${ }^{31}$ In the household decision model, instead, household members pool income $(0<\alpha \leq 1)$ and take joint decisions on the migration of their members. We assign individuals to households so that the within household correlation in risk aversion roughly resembles that in our data. Each household has four members, the average household size in our data, which results in 2,500 households in the simulation. Once households are formed, we randomly reassign migration costs to the household using the same distribution as above. Finally, we assume that migrants pool about a fourth of their income with the origin family (i.e. we set the parameter $\alpha=0.2$, corresponding to observed remittances ; see footnote 8), and that at most one individual can migrate from each household. As in our model, a household chooses to send a member to destination region $D$ if the utility is higher than the utility from keeping all members in source region $S$.

\footnotetext{
${ }^{30}$ These numbers correspond to what we report in section II: 5000 yuan is the average net income in rural areas, earnings in cities are approximately twice those in the countryside, and the coefficient of variation in rural areas is 0.58 (hence $3000 / 5000=0.6$ ).

${ }^{31}$ We assume migration costs are uncorrelated with risk attitudes. In our simulations, individuals are assigned a (pseudo) random value of migration cost drawn from a chi-squared distribution so that the mean value of migration costs is approximately equal to 30 percent of the expected earnings in the source region.
} 
Figure 5 plots the predicted migration rates and the average willingness to take risks among migrants and non-migrants for the two models. The horizontal axis carries the earnings variance in the destination region $D$ relative to the source region $S$, while the vertical axis carries the migration rate on the left-hand side and the average willingness to take risks on the right-hand side. In both models, the trend of the simulated migration rates are similar: when the variance at destination is lower than in the source region $\left(V\left(y_{D}\right) / V\left(y_{S}\right)<1\right)$ the migration rates (solid line) are close to $100 \%$, but they gradually decline as uncertainty in the destination region increases (relative to the source region). Similarly, both the individual and the household decision models imply that the selection of more risk tolerant individuals into migration leads to a higher average willingness to take risk for migrants (dash-dotted line) than for nonmigrants (dashed line) when there is lower uncertainty in the source region than in the destination. The two models diverge, however, in their quantitative predictions of the migration rate for any given level of relative earnings variance in the two regions. Whereas the individual model predicts a rapid decline in the share of migrants with increasing uncertainty in the destination region, such decline is less pronounced when migration decisions are taken at the household level. Thus, the household migration model predicts positive migration rates for levels of destination uncertainty for which an individual model would predict zero migration. It does so because first, the other household members benefit from risk diversification even if the earnings variance in the destination region is high and second, the migrant is partially insured against risks in the destination region by household members who stay at home. ${ }^{32}$ Both these factors are absent in a model in which migration decisions are made at the individual level.

\footnotetext{
${ }^{32}$ One can show that the lower is the share of income that the migrant pools with the rest of the family (parameter $\alpha$ in the model), the faster the migration rate drops as relative uncertainty in the destination region increases.
} 


\section{Discussion and Conclusions}

This paper analyses empirically the relation between the distribution of risk attitudes - within and across households - and migration decisions. It provides strong evidence not only that, in the context of internal migration in China, migration decisions are taken at the household level, but that heterogeneity in risk aversion within the household plays an important part in determining whether a migration takes place, who emigrates, and which households send migrants.

The insight that migration decisions, in the context that we analyse, but also likely in other settings, are taken at household level, and are influenced by risk attitudes of other household members has important policy implications. For instance, the implementation of a policy that creates possibilities to insure against risk - such as the introduction of social safety net schemes

- will possibly increase migrations if decisions are taken on an individual level. When the migration decision is taken at the household level, however, this may work in the opposite direction because it allows risk averse household members to diversify risk in other ways. Our model implies that household migration increases with the share of income pooled between migrant and non-migrant household members, as it allows other household members to diversify risk, and the migrant to insure against risk. Hence, the easier it is for households to transfer income back and forth between source and destination regions the higher will be the likelihood to engage in migration.

In demonstrating that the distribution of other household members' risk attitudes affects decisions to migrate, our analysis suggests that risk attitudes within the household may also affect other choices that are determined on a household level. Examples are the adoption of innovative farming practices, the selection of new crops, or the investment in a new family business, where decisions may be influenced by the distribution of risk attitudes within households and by the possible benefits of risk reduction to members other than the individuals 
directly concerned. Understanding direction and magnitude of the interactions between the effects of such decisions on different household members and their risk preferences should be an interesting avenue for future research, with the potential to contribute significantly to a better understanding of key economic decisions, particularly in developing countries.

\section{REFERENCES}

Barsky, Robert B., Juster, F. Thomas, Kimball, Miles S., and Shapiro, Matthew D., "Preference Parameters and Behavioral Heterogeneity: An Experimental Approach in the Health and Retirement Study," Quarterly Journal of Economics 112:2 (1997), 537-579.

Bonin, Holger, Dohmen, Thomas, Falk, Armin, Huffman, David, and Sunde, Uwe, “Crosssectional Earnings Risk and Occupational Sorting: The Role of Risk Attitudes," Labour Economics 14:6 (2007), 926-937.

Borghans, L., B. Golsteyn, J. Heckman and H. Meijers "Gender Differences in Risk Aversion and Ambiguity Aversion," Journal of the European Economic Association, 7:2-3, (2009), 649-658.

Borjas, George J., "Self-Selection and the Earnings of Immigrants," American Economic Review 77:4 (1987), 531-553.

Borjas, George J and Bratsberg, Bernt, "Who Leaves? The Outmigration of the Foreign-Born," The Review of Economics and Statistics, MIT Press, vol. 78(1) (1996), 165-76.

Brunnermeier Markus K. \& Stefan Nagel, 2008. "Do Wealth Fluctuations Generate TimeVarying Risk Aversion? Micro-evidence on Individuals," American Economic Review, American Economic Association, vol. 98(3), pages 713-36, June.

Bryan, Gharad, Chowdhury, Shyamal and Mobarak, Ahmed Mushfiq "Underinvestment in a Profitable Technology: The Case of Seasonal Migration in Bangladesh," Econometrica, Econometric Society, 82:09 (2014), 1671-1748. 
Chen, Kong-Pin. Chiang, Shin-Hwan, and Leung, Siu Fai, "Migration, Family, and Risk Diversification," Journal of Labor Economics 21:2 (2003), 323-352.

Chuang, Yating \& Schechter, Laura, 2015. "Stability of experimental and survey measures of risk, time, and social preferences: A review and some new results," Journal of Development Economics, Elsevier, vol. 117(C), pages 151-170

Chiappori, Pierre- André, Samphantharak, Krislert, Schulhofer- Wohl, Sam and Townsend, Robert M. "Heterogeneity and risk sharing in village economies," Quantitative Economics, Econometric Society, 5:03 (2014) 1-27.

Chiquiar, Daniel, and Hanson, Gordon H., "International Migration, Self-Selection, and the Distribution of Wages: Evidence from Mexico and the United States," Journal of Political Economy 113:2 (2005), 239-281.

de Brauw, Alan, and Mueller, Valerie. 2012. "Do Limitations in Land Rights Transferability Influence Low Mobility Rates in Ethiopia?” Journal of African Economies, 21(4), 54879.

Ding, Xiaohao, Hartog, Joop, and Sun, Yuze, "Can We Measure Individual Risk Attitudes in a Survey?” IZA discussion paper no. 4807 (2010).

Dohmen, Thomas, Falk, Armin, Huffman, David, Sunde, Uwe, Schupp, Jürgen and Gert. G. Wagner (2007), Risk as a personality trait: On the stability of risk attitudes, unpublished. Dohmen, Thomas, Falk, Armin, Huffman, David, and Sunde, Uwe, "Are Risk Aversion and Impatience Related to Cognitive Ability?" American Economic Review 100 (2010), $1238-1260$.

Dohmen Thomas, Falk, Armin, Huffman, David, and Sunde, Uwe, “The Intergenerational Transmission of Risk and Trust Attitudes," Review of Economic Studies 79:2 (2012), $645-677$. 
Dohmen Thomas, Falk, Armin, Huffman, David, Sunde, Uwe, Schupp, Jürgen, and Wagner, Gert G., "Individual Risk Attitudes: Measurement, Determinants, and Behavioral Consequences," Journal of the European Economic Association 9:3 (2011), 522-550.

Du Yang, Park, Albert, and Wang, Sangui (2005) "Migration and Rural Poverty in China", Journal of Comparative Economics, 33, 688-709.

Dustmann, Christian, "Return Migration, Uncertainty and Precautionary Savings," Journal of Development Economics, 52:2 (1997), 295-316.

Dustmann, Christian, Fadlon, Itzhak, and Weiss, Yoram, "Return Migration, Human Capital Accumulation and the Brain Drain," Journal of Development Economics 95:1 (2011), $58-67$.

Ekelund, J., Johansson, E., and Lichtermann, D., "Self-employment and Risk Aversion: Evidence from Psychological Test Data," Labour Economics 12 (2005), 649-659.

Frijters, Paul, Kong, Tao and Meng, Xin, "Migrant Entrepreneurs and Credit Constraints under Labour Market Discrimination," IZA Discussion Papers 5967 (2011).

Frijters, Paul, Gregory, Robert G., and Meng, Xin, 2015, “The Role of Rural Migrants in the Chinese Urban Economy," in Migration-Economic Change, Social Challenge, edited by Christian Dustmann (Oxford: Oxford University Press, 2015).

Frijters, P, Meng, X \& Resosudarmo, B., 2011, 'The effects of institutions on migrant wages in China and Indonesia', in Jane Golley and Ligang Song (ed.), Rising China: Global Challenges and Opportunities, ANU ePress, Canberra, pp. 245-284.

Gibson, J., and McKenzie, D., “The Microeconomic Determinants of Emigration and Return Migration of the Best and Brightest: Evidence from the Pacific," Journal of Development Economics 95 (2011), 18-29.

Gibson John \& David McKenzie \& Halahingano Rohorua \& Steven Stillman, 2016. "The Long-Term Impact of International Migration on Economic Decision-Making: Evidence 
from a Migration Lottery and Lab-in-the-Field Experiments," CReAM Discussion Paper Series 1614, Centre for Research and Analysis of Migration (CReAM), Department of Economics, University College London.

Giles, John, "Is Life More Risky in the Open? Household Risk-Coping and the Opening of China’s Labor Markets,” Journal of Development Economics 81:1 (2006), 25-60.

Giles John, and Yoo, Kyeongwon, "Precautionary Behavior, Migrant Networks, and Household Consumption Decisions: An Empirical Analysis Using Household Panel Data from Rural China," Review of Economics and Statistics 89:3 (2007), 534-551.

Giles, John T. \& Mu, Ren, 2014. "Village Political Economy, Land Tenure Insecurity, and the Rural to Urban Migration Decision: Evidence from China," IZA Discussion Papers 8630, Institute for the Study of Labor (IZA).

Gröger André \& Yanos Zylberberg, 2016. "Internal Labor Migration as a Shock Coping Strategy: Evidence from a Typhoon," American Economic Journal: Applied Economics, American Economic Association, vol. 8(2), pages 123-53

Guiso, Luigi, and Paiella, Monica, "Risk Aversion, Wealth and Background Risk," Journal of the European Economic Association 6:6 (2008), 1109-1150.

Hoddinott, John, "A Model of Migration and Remittances Applied to Western Kenya," Oxford Economic Papers, 46:3 (1994), 459-76, July.

Jaeger, David A., Dohmen, Thomas, Falk, Armin., Huffman, David, Sunde, Uwe, and Bonin, Holger, "Direct Evidence on Risk Attitudes and Migration," Review of Economics and Statistics 92:3 (2010), 684-689.

Jalan, Jyotsna, and Ravallion, Martin, "Are the Poor Less Well Insured? Evidence on Vulnerability to Income Risk in Rural China," Journal of Development Economics 58:1 (1999), 61-81. 
Levine, Ross and Rubinstein, Yonas, "Smart and elicit: Who becomes an Entrepreneur and does it pay?" CEP DP No. 1237 (2014).

Liu, Elaine M. "Time to Change What to Sow: Risk Preferences and Technology Adoption Decisions of Cotton Farmers in China," The Review of Economics and Statistics, MIT Press, 95:4 (2013), 1386-1403.

Mazzocco, Maurizio "Savings, Risk Sharing and Preferences for Risk," American Economic Review 94:4 (2004), 1169-1182.

Mazzocco, Maurizio and Saini, Shiv, 2012. "Testing Efficient Risk Sharing with Heterogeneous Risk Preferences," American Economic Review 102:1 (2012), 428-68.

McKenzie, David and Rapoport, Hillel, "Self-Selection Patterns in Mexico-U.S. Migration: The Role of Migration Networks," Review of Economics and Statistics 92:4 (2010), 811821.

Meng, Xin, "Labor Market Outcomes and Reforms in China," Journal of Economic Perspectives 26:4 (2012), 75-102.

Meng, Xin, and Manning, Chris, "The Great Migration in China and Indonesia-Trend and Institutions." Chap. 1 in The Great Migration: Rural-Urban Migration in China and Indonesia, edited by X. Meng and C. Manning, with S. Li, and T. Effendi, Edward Elgar Publishing, (2010).

Meng, Xin, Xue, Sen, and Xue, Jinjun, 2016, “Consumption and savings of migrant households: 2008-2014”, Chapter 8 in Ligang Song, Ross Garnaut, Cai Fang and Lauren Johnston (eds), China's New Sources of Economic Growth, the ANU Press, the Australian National University, Canberra, pp. 159-195.

Meng, Xin, and Zhang, Junsen, "The Two-Tier Labor Market in Urban China: Occupational Segregation and Wage Differentials between Urban Residents and Rural Migrants in Shanghai," Journal of Comparative Economics 29:3 (2001), 485-504. 
Morten, Melanie, "Temporary Migration and Endogenous Risk Sharing in Village India," mimeo, Yale University (2013).

Munshi Kaivan \& Mark Rosenzweig, 2016. "Networks and Misallocation: Insurance, Migration, and the Rural-Urban Wage Gap," American Economic Review, American Economic Association, vol. 106(1), pages 46-98

Rosenzweig, Mark R., and Stark, Oded, "Consumption Smoothing, Migration, and Marriage: Evidence from Rural India,” Journal of Political Economy 97:4 (1989), 905-926.

Rozelle, Scott, J. Edward Taylor, and Alan deBrauw, "Migration, Remittances, and Agricultural Productivity in China,” American Economic Review 89:2 (1999), 287-291.

Stark, Oded, and Levhari, David, "On Migration and Risk in LDCs," Economic Development and Cultural Change 31:1 (1982), 191-196.

Taylor, J Edward, Rozelle, Scott and de Brauw, Alan, "Migration and Incomes in Source Communities: A New Economics of Migration Perspective from China," Economic Development and Cultural Change 52:1 (2003), 75-101.

Valsecchi, Michele, 2014. "Land property rights and international migration: Evidence from Mexico," Journal of Development Economics, Elsevier, vol. 110(C), pages 276-290.

Zhao, Jiaying, Edward Jow-Ching Tu, Christine McMurray \& Adrian Sleigh, "Rising mortality from injury in urban China: demographic burden, underlying causes and policy implications", Bulletin of the World Health Organization 90 (2012) 461-467

Wooldridge Jeffrey, M. (2002). "Econometric analysis of cross section and panel data". Cambridge, MA: Massachusetts Institute of Technology. 


\section{Figures}

FIGURE 1.-ModEL

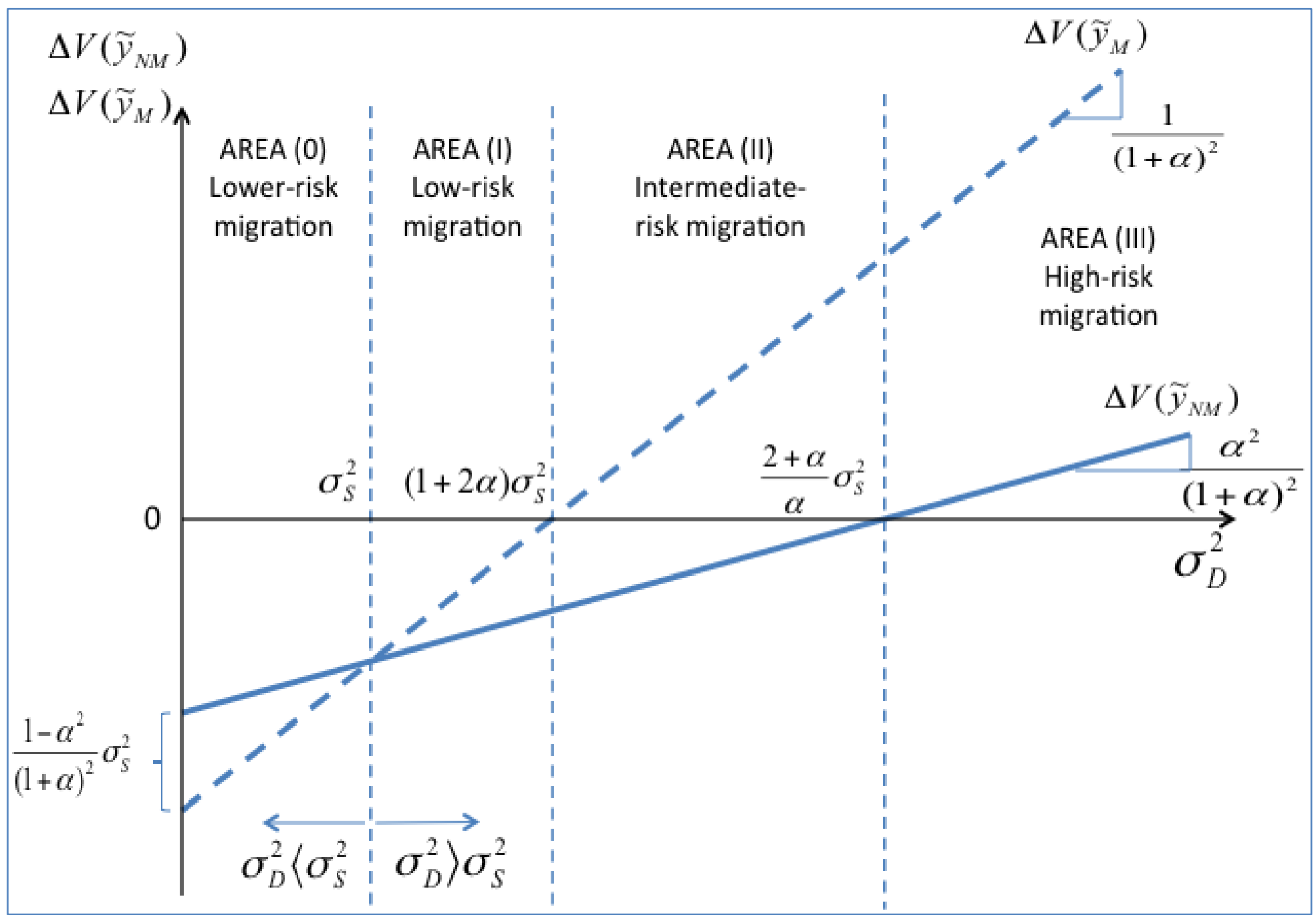




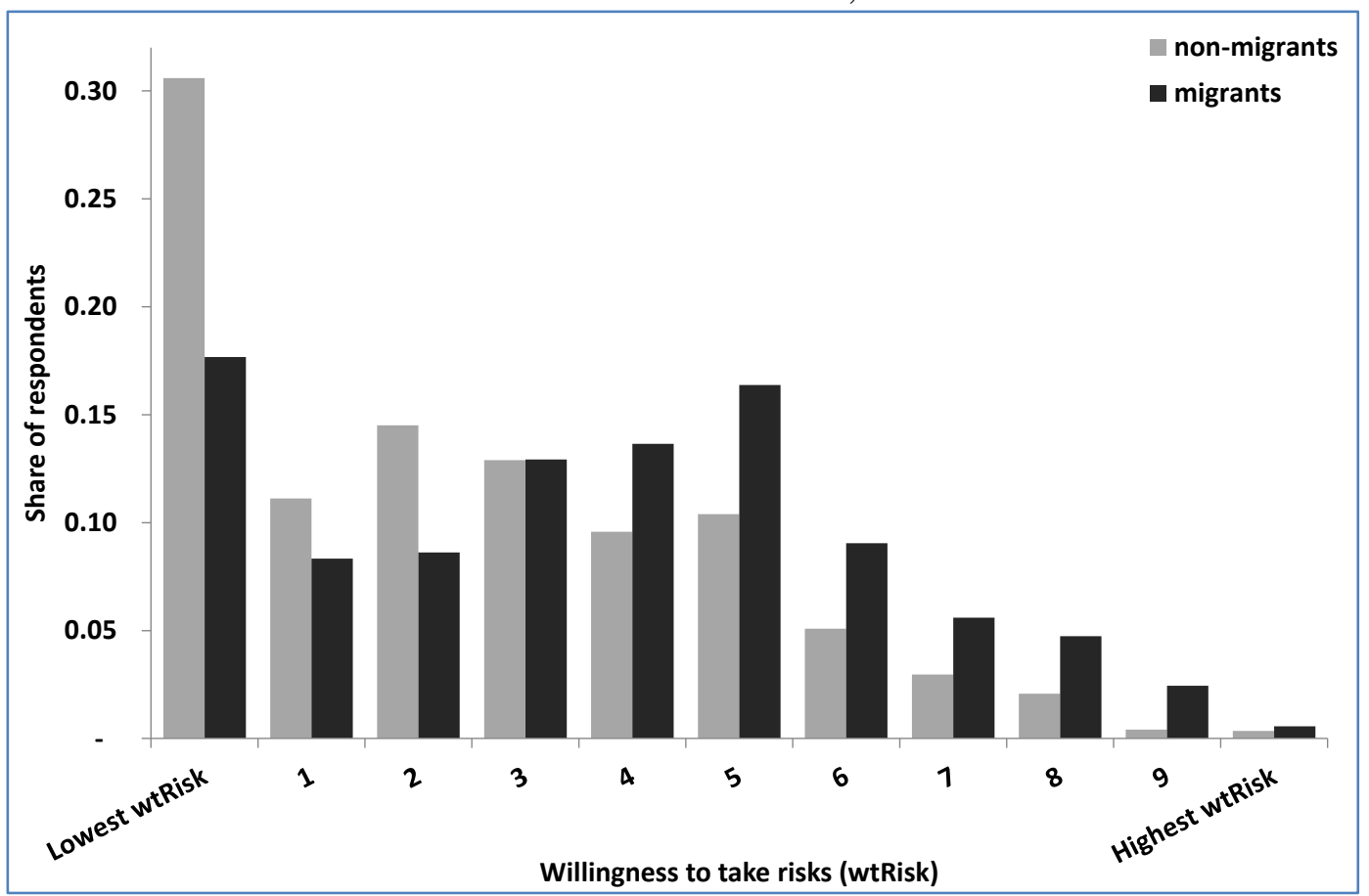

Note. The measure (wtRisk) varies between 0 (lowest level of willingness to take risk) and 10 (highest level of willingness to take risk). Source: RUMiC -RHS Survey.

\section{FIGURE 3.- INDIVIDUAL WILLINGNESS TO TAKE RISKS AND HOUSEHOLD AVERAGE}

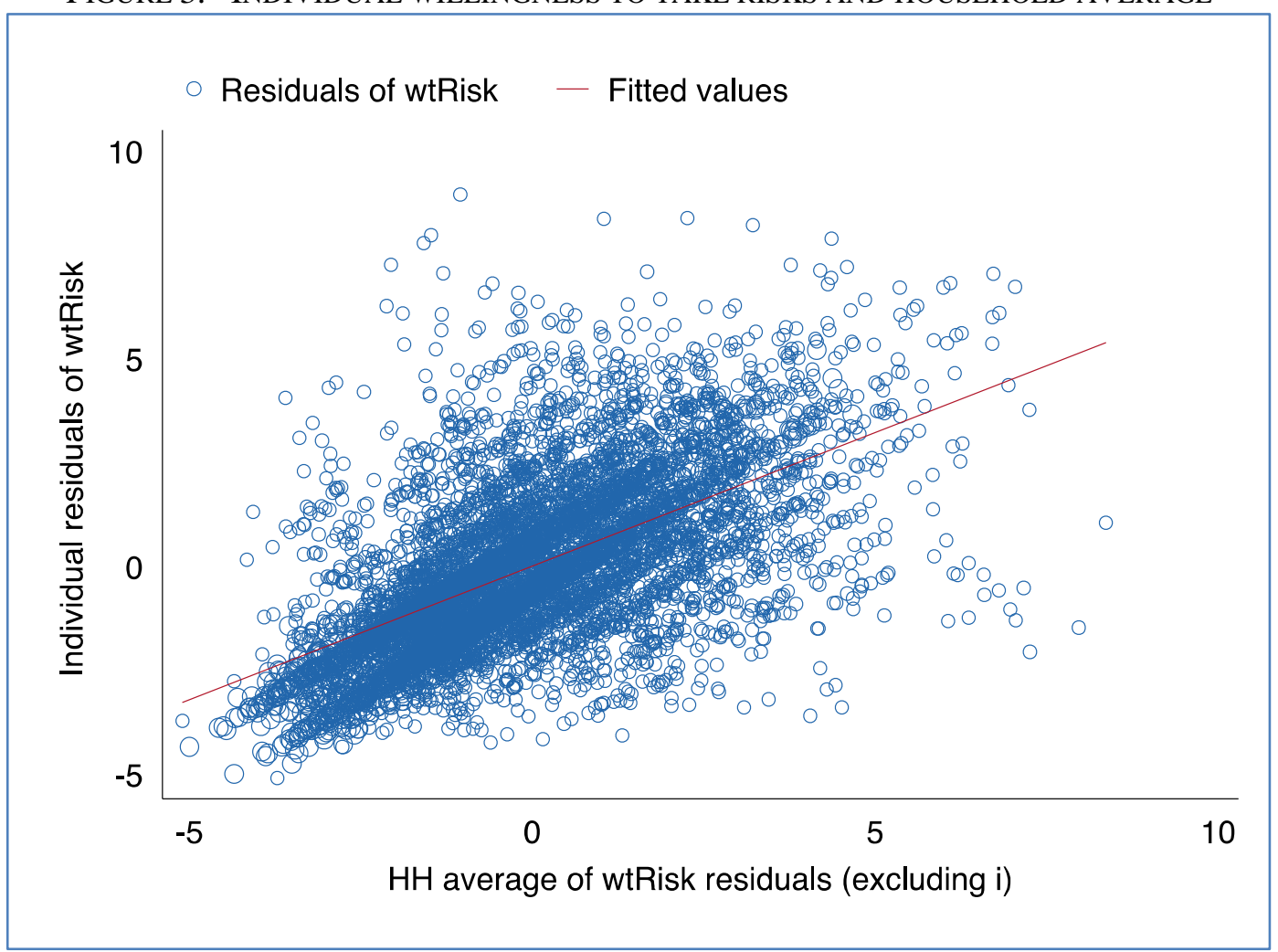

Note: The scatter plot shows residual willingness to take risks for each individual in our estimating sample (vertical axis) versus the average residual willingness to take risks of other members in the household (horizontal axis). Residuals are obtained by regressing individual willingness to take risks on basic demographic controls (gender, age, and age squared) and a full set of county of residence dummies. The figure shows the regression fitted line (correlation $=0.58$ ). 
Panel A: Migrated last year
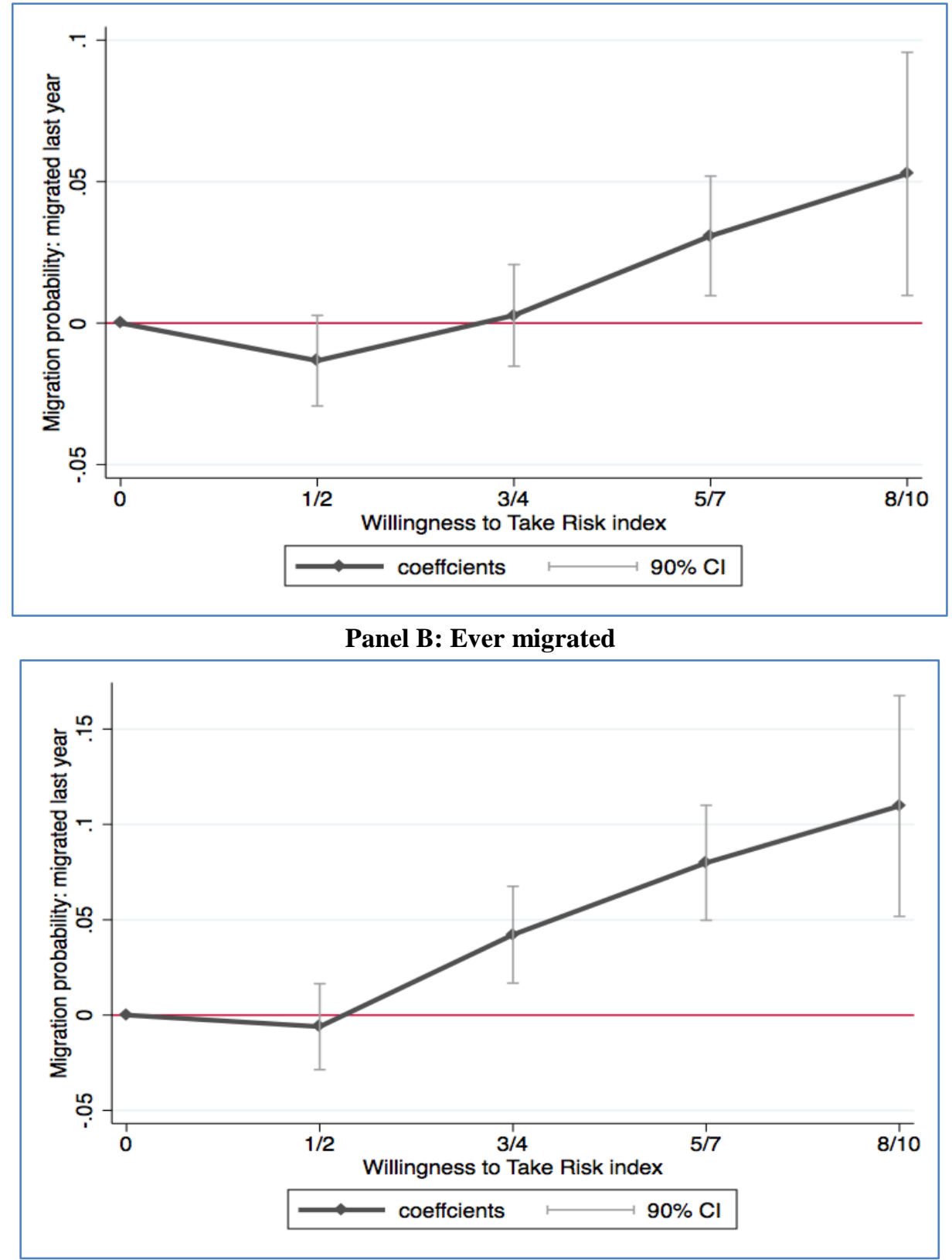

Note. In panel A, individuals are defined as migrant if they migrated for work during the year before the survey; in Panel B, if they ever migrated for work in the past. Individual probabilities of being a migrant are regressed on five dummy variables identifying different levels of willingness to take risks in which the excluded category corresponds to a willingness to take risks equal to zero. The graph plots the estimated coefficients on these dummies together with their $90 \%$ confidence intervals. Included in the regressions are individual controls (age, age squared, a dummy for male, years of education, a dummy for married relation with $\mathrm{HH}$ head dummies, order of birth, number of siblings, and number of children) and household controls (number of family members under 16 , in the work force, and older than 60; per capita house value (in logs)), and 82 county dummies. 
FIGURE 5.-INDIVIDUAL AND HOUSEHOLD MIGRATION DECISION MODELS

PANEL A: INDIVIDUAL MIGRATION DECISION MODEL

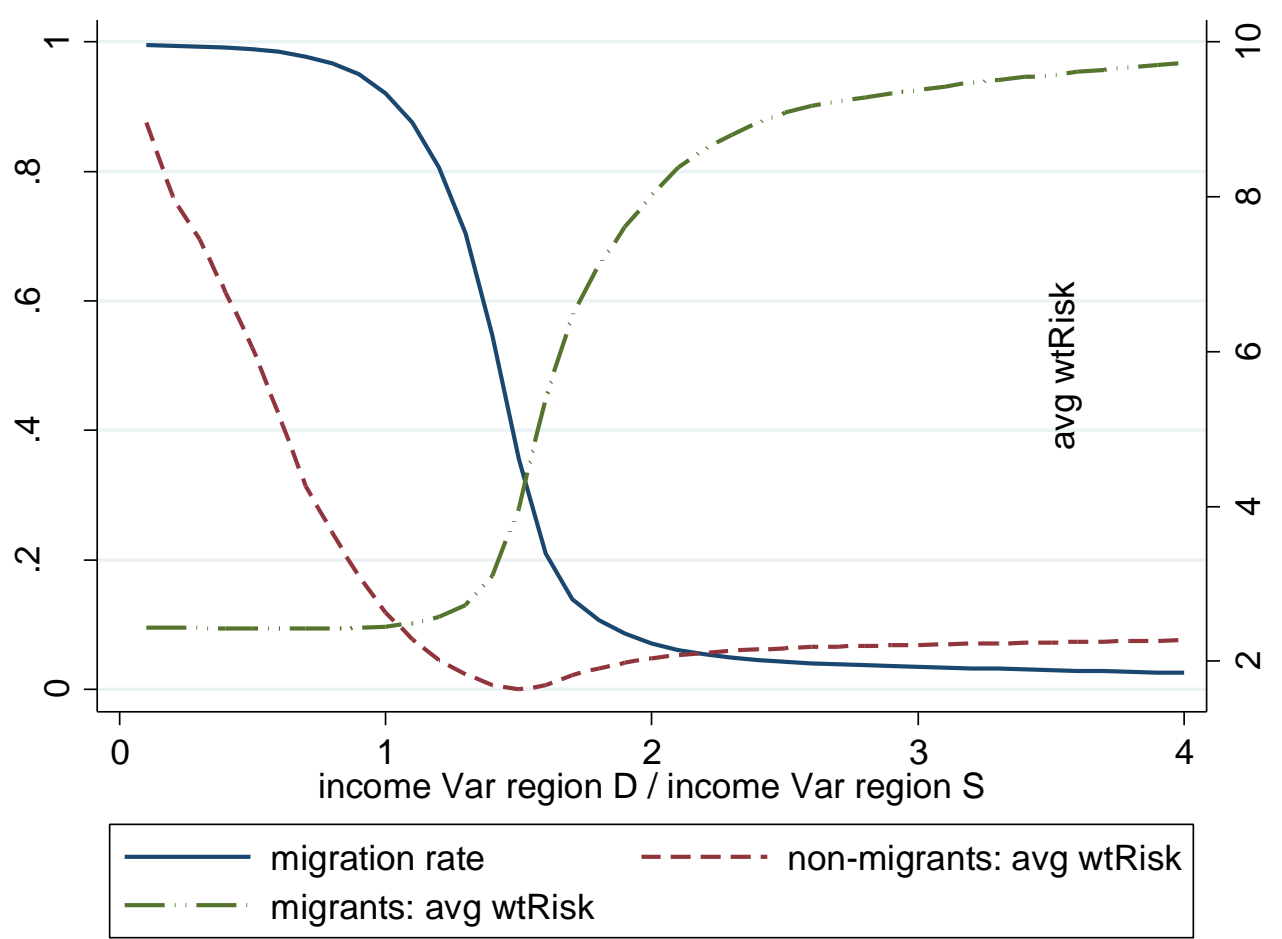

PANEL B: HOUSEHOLD MIGRATION DECISION MODEL

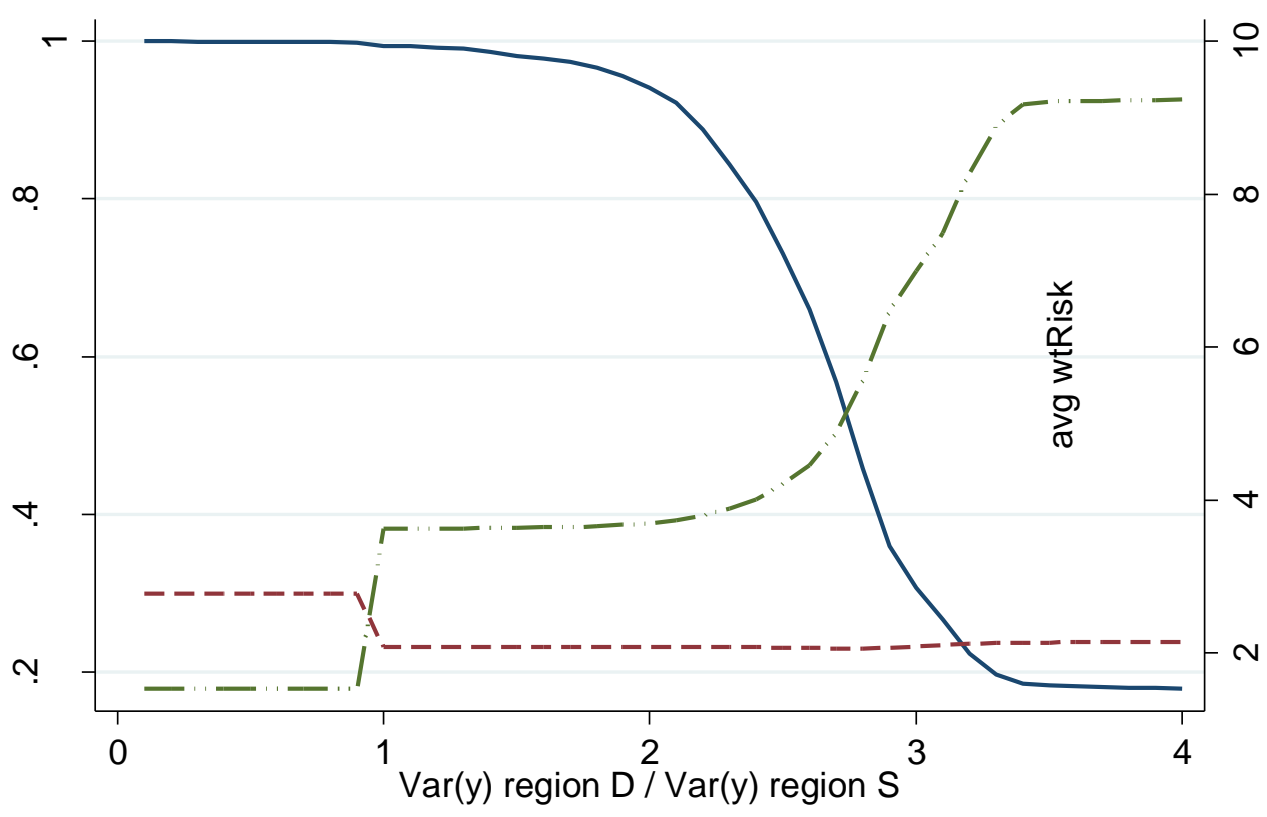

- HH migration rate $\quad----\cdot$ non-migrants: avg wtRisk

_-.. migrants: avg wtRisk

Note. These figures are obtained from the simulation described in section VI. 


\section{Tables}

Table 1.-Descriptive STATISTICS

\begin{tabular}{lccccc}
\hline \multicolumn{1}{c}{ Variable } & Mean & Std. Dev. & Min & Max & Obs \\
\cline { 2 - 6 } Male & \multicolumn{5}{c}{ Individuals } \\
Age & 0.50 & 0.50 & 0 & 1 & 6,332 \\
Married & 43.82 & 10.65 & 16 & 60 & 6,332 \\
Years of education & 0.92 & 0.27 & 0 & 1 & 6,332 \\
Birth order & 7.15 & 2.83 & 0 & 13 & 6,332 \\
Number of siblings & 2.24 & 1.33 & 0 & 10 & 6,123 \\
Number of child & 3.15 & 1.64 & 0 & 11 & 6,250 \\
Willingness to take risks (wtRisk) & 1.68 & 0.99 & 0 & 7 & 6,332 \\
Migrated last year & 2.57 & 2.36 & 0 & 10 & 6,332 \\
Ever migrated & 0.11 & 0.31 & 0 & 1 & 6,332 \\
& 0.23 & 0.42 & 0 & 1 & 6,280 \\
\hline Household size & & & Households & \\
HH members aged <16 & 4.08 & 1.32 & 2 & 11 & 2,961 \\
HH members in the work force & 0.57 & 0.73 & 0 & 5 & 2,961 \\
HH members aged >60 & 2.89 & 1.09 & 1 & 8 & 2,961 \\
HH head's education (years) & 0.34 & 0.61 & 0 & 4 & 2,961 \\
Plot size (Mu, 15Mu = 1 hectare) & 7.25 & 2.58 & 0 & 12 & 2,961 \\
House value per capita (Yuan, in logs) & 4.12 & 4.08 & 0 & 75 & 2,961 \\
HH avg willingness to take risks & 9.16 & 1.33 & 1.20 & 14.04 & 2,961 \\
At least one HH member migrated last yearyyyyyyyyy & 2.46 & 2.03 & 0 & 10 & 2,961 \\
\hline & 0.16 & 0.36 & 0 & 1 & 2,961 \\
\hline
\end{tabular}

Note. The sample includes all individuals in the labour force (i.e. aged between 16 and 60 and not currently in school or disabled) who live in households in which more than one member in the labour force has reported risk attitudes.

Source: 2009 RUMiC-RHS Survey. 
Table 2.-INDIVIDUAL MigRATION DECISION

\begin{tabular}{|c|c|c|c|c|c|c|c|c|c|c|}
\hline & \multicolumn{5}{|c|}{ Migrated last year } & \multicolumn{5}{|c|}{ Ever migrated } \\
\hline & (1) & (2) & (3) & (4) & (5) & (6) & (7) & (8) & (9) & (10) \\
\hline \multirow[t]{2}{*}{ wtRisk } & $0.014 * * *$ & $0.005^{* * *}$ & $0.005^{* * *}$ & $0.005^{* * *}$ & & $0.030 * * *$ & $0.014 * * *$ & $0.014 * * *$ & $0.014 * * *$ & \\
\hline & $(0.0018)$ & $(0.0019)$ & $(0.0019)$ & $(0.0019)$ & & $(0.0025)$ & $(0.0027)$ & $(0.0028)$ & $(0.0028)$ & \\
\hline \multirow[t]{2}{*}{ wtRisk * male } & & & & & $0.006 * *$ & & & & & $0.014 * * *$ \\
\hline & & & & & $(0.002)$ & & & & & $(0.003)$ \\
\hline \multirow[t]{2}{*}{ wtRisk * female } & & & & & $0.005 * *$ & & & & & $0.013^{* * *}$ \\
\hline & & & & & $(0.002)$ & & & & & $(0.003)$ \\
\hline Basic individual controls & & $\mathrm{X}$ & $x$ & $\mathrm{X}$ & $\mathrm{X}$ & & $\mathrm{X}$ & $x$ & $\mathrm{X}$ & $\mathrm{X}$ \\
\hline Additional individual controls & & & $x$ & $x$ & $x$ & & & $x$ & $x$ & $x$ \\
\hline Household controls & & & & $x$ & $\mathrm{X}$ & & & & $\mathrm{X}$ & $x$ \\
\hline County fixed effects & $x$ & $x$ & $x$ & $x$ & $x$ & $x$ & $x$ & $x$ & $x$ & $x$ \\
\hline Observations & 6,332 & 6,332 & 6,103 & 5,992 & 5,992 & 6,280 & 6,280 & 6,052 & 5,946 & 5,946 \\
\hline R-squared & 0.187 & 0.288 & 0.305 & 0.310 & 0.310 & 0.148 & 0.273 & 0.288 & 0.292 & 0.292 \\
\hline
\end{tabular}

Note. The table reports estimates from LPM regressions of a dummy for individual migration status on individual willingness to take risk ( $w t R i s k$ ) and other controls. The migration status dummy equals one if the individual migrated for work in the year before the interview (columns 1-5) or had ever migrated for work (columns 6-10). The wtRisk variable measures individual willingness to take risks (decreasing with risk aversion) and has a mean of 2.57 and a standard deviation of 2.36 . In column 5 and 10 , the variable wtRisk is interacted with a male and a female dummy. The basic individual controls are age, age squared, a dummy for male, years of education, and a dummy for married; the additional individual controls are a dummy for relation to head of household, order of birth, number of siblings, and number of children; and the household controls are household size and structure (number of family members under 16, in the work force, and older than 60); and per capita house value (in logs). All regressions include 82 county fixed effects. The sample includes all individuals in the labour force (i.e. aged between 16 and 60 and not currently in school or disabled) who live in households in which more than one member in the labour force has reported risk attitudes. Robust standard errors are clustered at the household level and reported in brackets. $* * *$ p $<0.01$, $* * \mathrm{p}<0.05, * \mathrm{p}<0.1$. 
Table 3.-Within Household Migration Decision: Relative MEASURE ANd Risk PREFERENCES OF Other HousEHOLD MEMBERS

\begin{tabular}{|c|c|c|c|c|c|c|c|}
\hline & (1) & (2) & (3) & (4) & (5) & (6) & (7) \\
\hline \multirow[t]{2}{*}{ wtRisk } & $0.005^{* * *}$ & & $0.003 *$ & & $0.005^{* * *}$ & & $0.009 * * *$ \\
\hline & $(0.002)$ & & $(0.002)$ & & $(0.002)$ & & $(0.002)$ \\
\hline \multirow[t]{2}{*}{ wtRisk_rel: ranking in $\mathrm{HH}$ normalised } & & $0.070 * * *$ & $0.055^{* * *}$ & & & & \\
\hline & & $(0.018)$ & $(0.020)$ & & & & \\
\hline \multirow[t]{2}{*}{ wtRisk_rel: Dummy for highest wtRisk in HH } & & & & $0.016^{* *}$ & $0.014^{*}$ & & \\
\hline & & & & $(0.008)$ & $(0.008)$ & & \\
\hline \multirow[t]{2}{*}{ wtRisk_oth: Average wtRisk of other HH members } & & & & & & -0.000 & $-0.006 * * *$ \\
\hline & & & & & & $(0.002)$ & $(0.002)$ \\
\hline Individual controls & $x$ & $x$ & $x$ & $x$ & $\mathrm{x}$ & $x$ & $x$ \\
\hline Household controls & $x$ & $x$ & $x$ & $x$ & $x$ & $x$ & $x$ \\
\hline County fixed effects & $x$ & $x$ & $x$ & $x$ & $x$ & $x$ & $\mathrm{x}$ \\
\hline Observations & 5,992 & 5,992 & 5,992 & 5,992 & 5,992 & 5,992 & 5,992 \\
\hline R-squared & 0.310 & 0.310 & 0.311 & 0.309 & 0.310 & 0.309 & 0.311 \\
\hline
\end{tabular}

Note. The table reports the estimates from LPM regressions of a dummy for individual migration status (in the previous year) on different measures of willingness to take risks (at both the individual and household level) and other controls. The wtRisk variable measures individual willingness to take risk (which decreases with risk aversion) and has a mean of 2.57 and a standard deviation of 2.36. Columns 2-9 include two alternative measures of the individual's position in the household ranking of willingness to take risk among members in the work force (i.e. aged between 16 and 60 and not currently in school or disabled): (i) individual ranking in risk attitudes within the household, obtained by ranking household members by their willingness to take risks, assigning a value of one to the most risk-averse person and progressively higher values to the other members, and then normalizing this measure by the number of members reporting risk preferences (columns 2-3); (ii) an indicator for the individual having the highest willingness to take risks in the household (columns 4-5). In columns 6-7, we include the average risk preferences of the other household members who are in the workforce (wtRisk_oth). The individual controls are age, age squared, a dummy for male, years of education, a dummy for married, relation with HH head dummies, order of birth, number of siblings, and number of children; and the household controls are household size and structure (number of family members under 16, in the work force, and older than 60); and per capita house value (in logs). All specifications include county fixed effects. The sample includes all individuals in the work force (i.e. aged between 16 and 60 and not currently in school or disabled) who live in households in which more than one member in the work force has reported risk attitudes. Robust standard errors are clustered at the household level and reported in brackets. $* * * \mathrm{p}<0.01, * * \mathrm{p}<0.05, * \mathrm{p}<0.1$. 
Table 4.-ACROSS HouseHOLD Migration DeCision (A)

\begin{tabular}{|c|c|c|c|c|}
\hline & (1) & $(2)$ & (3) & (4) \\
\hline \multirow[t]{2}{*}{ HH_avg_wtRisk } & $0.010 * * *$ & 0.004 & $0.009 * * *$ & 0.003 \\
\hline & $(0.003)$ & $(0.004)$ & $(0.003)$ & $(0.004)$ \\
\hline \multirow[t]{2}{*}{ HH_range_wtRisk } & & $0.017^{* * *}$ & & $0.016^{* * *}$ \\
\hline & & $(0.004)$ & & $(0.004)$ \\
\hline Household controls & & & $x$ & $x$ \\
\hline County fixed effects & $x$ & $x$ & $x$ & $x$ \\
\hline Observations & 2,961 & 2,961 & 2,961 & 2,961 \\
\hline R-squared & 0.306 & 0.311 & 0.314 & 0.319 \\
\hline
\end{tabular}

Note. The table reports estimates from LPM regressions of a dummy that equals one if the household has at least one migrant member in the labour force on different household-level measures of willingness to take risks and other controls. The variables HH_avg_wtRisk and HH_range_wtRisk measure the average and the range of willingness to take risks in the household, respectively. The household controls are household size and structure (number of family members under 16, in the work force, and older than 60); per capita house value (in logs); size of the family plot; and the years of education and age of the head of household. All specifications include 82 county fixed effects. The sample includes all households in which at least two individuals have reported risk attitudes, and at least one of these is in the labour force (i.e. aged between 16 and 60 and not currently in school or disabled). Robust standard errors are reported in brackets. $* * * \mathrm{p}<0.01, * * \mathrm{p}<0.05, * \mathrm{p}<0.1$. 
Table 5.- Across Household MigRation DeCision (B)

\begin{tabular}{|c|c|c|c|c|c|c|c|}
\hline & & (1) & (2) & (3) & (4) & (5) & (6) \\
\hline \multirow{2}{*}{\multicolumn{2}{|c|}{ HH_max_wtRisk }} & $0.012^{* * *}$ & $0.017^{* * *}$ & $0.011 * * *$ & $0.015^{* * *}$ & $0.016 * * *$ & $0.017 * * *$ \\
\hline & & $(0.003)$ & $(0.004)$ & $(0.003)$ & $(0.004)$ & $(0.004)$ & $(0.004)$ \\
\hline \multirow{2}{*}{\multicolumn{2}{|c|}{ HH_oth_wtRisk }} & & $-0.009 *$ & & -0.008 & $-0.012^{* *}$ & $-0.012 * *$ \\
\hline & & & $(0.005)$ & & $(0.005)$ & $(0.006)$ & $(0.006)$ \\
\hline \multicolumn{2}{|c|}{ Household controls } & & & $x$ & $x$ & & $x$ \\
\hline \multicolumn{2}{|c|}{ County fixed effects } & $x$ & $x$ & $x$ & $x$ & $\mathrm{X}$ & $x$ \\
\hline \multirow[t]{2}{*}{ WF age range: } & $16-60$ & $x$ & $\mathrm{X}$ & $x$ & $x$ & & \\
\hline & $16-50$ & & & & & $x$ & $x$ \\
\hline \multicolumn{2}{|l|}{ Observations } & 2,961 & 2,961 & 2,961 & 2,961 & 2,189 & 2,189 \\
\hline \multicolumn{2}{|l|}{ R-squared } & 0.310 & 0.311 & 0.317 & 0.318 & 0.350 & 0.356 \\
\hline
\end{tabular}

Note. The table reports estimates from LPM regressions of a dummy that equals one if the household has at least one migrant member in the labour force on the risk preferences of the individual with the highest willingness to take risks in the household ( $H H_{-}$max_wtRis $k_{h k}$ ), the average risk attitudes among the other household members (HH_oth_wtRisk ${ }_{h k}$ ) and other controls. In columns 1-4, the age bracket for workers to be considered part of the workforce is 16-60; in columns 5-6 it is 16-50. The household controls are household size and structure (number of family members under 16, in the work force, and older than 60); per capita house value (in logs); size of the family plot; and years of education and age of the head of household. All specifications include 82 county fixed effects. The sample includes all households in which at least two individuals have reported risk attitudes, and at least one of these is in the work force (i.e. within the defined age bracket and not currently in school or disabled). Robust standard errors are reported in brackets. *** $\mathrm{p}<0.01, * * \mathrm{p}<0.05,{ }^{*} \mathrm{p}<0.1$. 


\section{Appendix (for Online Publication)}

\section{A.I. Theoretical Framework}

\section{A. Proof of Proposition 1}

Assume that individual 1 is more risk averse than individual 2 so that $k_{1}>k_{2}$. Then the difference in household utility when individual 2 emigrates instead of individual 1 is

$$
\begin{gathered}
U_{S D}(1=N M ; 2=M)-U_{S D}(1=M ; 2=N M)= \\
=\left[E\left(\tilde{y}^{N M}\right)-k_{1} V\left(\tilde{y}^{N M}\right)+E\left(\tilde{y}^{M}\right)-k_{2} V\left(\tilde{y}^{M}\right)\right]-\left[E\left(\tilde{y}^{M}\right)-k_{1} V\left(\tilde{y}^{M}\right)+\right. \\
\left.+E\left(\tilde{y}^{N M}\right)-k_{2} V\left(\tilde{y}^{N M}\right)\right]=\left(k_{1}-k_{2}\right)\left[V\left(\tilde{y}^{M}\right)-V\left(\tilde{y}^{N M}\right)\right]
\end{gathered}
$$

The first term is positive because $k_{1}>k_{2}$. The sign of the second term depends on the relative size of the earnings variance of being a migrant vs. not being a migrant, although it will always be positive as long as ${\sigma_{\mathrm{D}}}^{2} \geq{\sigma_{\mathrm{S}}}^{2}$ (see proposition 1). Hence, as long as the earnings variance is higher for the migrant, which in our setting will always be the case if the earnings variance is larger in the destination (see Figure 1), it is optimal to choose the least risk averse individual in the household as the potential migrant. Nevertheless, it may still be that $\mathrm{U}_{\mathrm{SD}}<\mathrm{U}_{\mathrm{SS}}$, so that it is optimal for the household to send no migrant.

\section{B. Proof of Proposition 2}

Given two households, $h_{A}$ and $h_{B}$, which differ only in the degree of their members' risk aversion, then it follows from proposition 1 that in both households, if a migrant is sent, it will be the member with the lowest risk aversion. Assuming that in both households individual 2 is less risk averse than individual 1, each household will evaluate whether the household utility increases when individual 2 migrates compared to the non-migration option. For both households, the utility gain from migration is

$$
\Delta U^{j}=\Delta E\left(\tilde{y}^{N M}\right)-k_{1}^{j} \Delta V\left(\tilde{y}^{N M}\right)+M E\left(\tilde{y}^{M}\right)-k_{2}^{j} \Delta V\left(\tilde{y}^{M}\right) \quad j=h_{A}, h_{B}
$$

Which household gains the most from migration depends on the difference in utility gains: 


$$
\Delta U^{h_{B}}-\Delta U^{h_{A}}=\Delta V\left(\tilde{y}^{N M}\right)\left(k_{1}^{h_{A}}-k_{1}^{h_{B}}\right)+\Delta V\left(\tilde{y}^{M}\right)\left(k_{2}^{h_{A}}-k_{2}^{h_{B}}\right)
$$

We can now prove statements (i) and (ii) of proposition 2:

(i) Supposing that the two households have the same average risk aversion $\left(\bar{k}^{h_{A}}=\bar{k}^{h_{B}}\right)$ but differ in the within household variance in risk attitudes, $k_{1}^{h_{A}}-k_{2}^{h_{A}} \neq k_{1}^{h_{B}}-k_{2}^{h_{B}}$, we can substitute $k_{1}^{h_{A}}=2 \bar{k}^{h_{A}}-k_{2}^{h_{A}}$ and $k_{1}^{h_{B}}=2 \bar{k}^{h_{B}}-k_{2}^{h_{B}}$ into A.3:

$$
\begin{gathered}
\Delta U^{h_{B}}-\Delta U^{h_{A}}=\Delta V\left(\tilde{y}^{N M}\right)\left(2 \bar{k}^{h_{A}}-k_{2}^{h_{A}}-2 \bar{k}^{h_{B}}+k_{2}^{h_{B}}\right)+\Delta V\left(\tilde{y}^{M}\right)\left(k_{2}^{h_{A}}-k_{2}^{h_{B}}\right)= \\
=\left(k_{2}^{h_{B}}-k_{2}^{h_{A}}\right)\left(\Delta V\left(\tilde{y}^{N M}\right)-\Delta V\left(\tilde{y}^{M}\right)\right)
\end{gathered}
$$

Given that $\Delta V\left(\tilde{y}^{N M}\right)<\Delta V\left(\tilde{y}^{M}\right)$ (for $\sigma_{\mathrm{D}}^{2} \geq \sigma_{\mathrm{S}}^{2}$; see section IIB), household $\mathrm{B}$ will benefit more from migration $\left(\Delta U^{h_{B}}>\Delta U^{h_{A}}\right)$ if its least risk averse member is less risk averse than the least risk averse member of household $\mathrm{A}\left(k_{2}^{h_{B}}<k_{2}^{h_{A}}\right)$. Having assumed that the average risk aversion in the two households is the same, this last condition implies also that the most risk averse individual in household $\mathrm{B}$ must be more risk averse than the most risk averse individual in household $\mathrm{A}\left(k_{1}^{h_{B}}>k_{1}^{h_{A}}\right)$. Hence, for household $\mathrm{B}$ to benefit more from migration than household $\mathrm{A}$, the risk attitudes of household members must be more heterogeneous.

(ii) Assuming that member 1 has the same level of risk aversion in both households $\left(\mathrm{k}_{1}^{h_{A}}=\mathrm{k}_{1}^{h_{B}}\right)$, while member 2 is less risk averse in household $2\left(\mathrm{k}_{2}^{h_{A}}>\mathrm{k}_{2}^{h_{B}}\right)$, then the difference in utility gain reduces to

$$
\Delta U^{h_{B}}-\Delta U^{h_{A}}=\Delta V\left(\tilde{y}^{M}\right)\left(k_{2}^{h_{A}}-k_{2}^{h_{B}}\right)
$$

so that $\Delta \mathrm{U}^{h_{B}}>\Delta \mathrm{U}^{h_{A}}$ as long as $\Delta V\left(\tilde{y}^{M}\right)>0$ (areas II and III in Figure 1) and $\Delta \mathrm{U}^{h_{B}}<\Delta \mathrm{U}^{h_{A}}$ if $\Delta V\left(\tilde{y}^{M}\right)<0$ (area I in Figure 1). That is, if migrating increases (reduces) the exposure to risk of the migrant member, the household that gains most from migration is the household in which individual 2 (i.e. the least risk averse in her own household) is less (more) risk averse. 
Supposing instead that member 2 (with the lowest risk aversion in each household) has the same level of risk aversion $\left(\mathrm{k}_{2}^{h_{A}}=\mathrm{k}_{2}^{h_{B}}\right)$ in both households while member 1 is less risk averse in household $2\left(\mathrm{k}_{1}^{h_{A}}>\mathrm{k}_{1}^{h_{B}}\right)$, then the difference in utility gains from migration between the two households is

$$
\Delta U^{h_{B}}-\Delta U^{h_{A}}=\Delta V\left(\tilde{y}^{N M}\right)\left(k_{1}^{h_{A}}-k_{1}^{h_{B}}\right)
$$

Now, $\Delta \mathrm{U}^{h_{B}}>\Delta \mathrm{U}^{h_{A}}$ as long as $\Delta V\left(\tilde{y}^{N M}\right)>0$ (area III in Figure 1) and $\Delta \mathrm{U}^{h_{B}}<\Delta \mathrm{U}^{h_{A}}$ if $\Delta V\left(\tilde{y}^{M}\right)<0$ (area I and II in Figure 1). In other words, if migration exposes the non-migrant individual to lower (higher) uncertainty, the household gaining the most from migration is the household where individual 1 is less (more) risk averse.

\section{Extension: Non-Zero Correlation $\left(\boldsymbol{\sigma}_{\boldsymbol{S D}} \neq \mathbf{0}\right)$}

Assuming now that $\operatorname{Cov}\left(\varepsilon_{S} \varepsilon_{D}\right)=\sigma_{S D} \neq 0$, the household utility from sending one migrant to region $\mathrm{D}$ is

$$
\begin{gathered}
U_{S D}=\left[E\left(\tilde{y}^{N M}\right)-k_{1} V\left(\tilde{y}^{N M}\right)\right]+\left[E\left(\tilde{y}^{M}\right)-k_{2} V\left(\tilde{y}^{M}\right)\right]= \\
=\underbrace{\left[\left(\frac{\bar{y}_{\mathrm{S}}+\alpha\left(\bar{y}_{\mathrm{D}}-c\right)}{1+\alpha}\right)-k_{1}\left(\frac{\sigma_{S}^{2}+\alpha^{2} \sigma_{D}^{2}+2 \alpha \sigma_{S D}}{(1+\alpha)^{2}}\right)\right]}_{N M}+\underbrace{\left[\left(\frac{\alpha \bar{y}_{\mathrm{S}}+\left(\bar{y}_{\mathrm{D}}-c\right)}{1+\alpha}\right)-k_{2}\left(\frac{\alpha^{2} \sigma_{S}^{2}+\sigma_{D}^{2}+2 \alpha \sigma_{S D}}{(1+\alpha)^{2}}\right)\right]}_{M}
\end{gathered}
$$

The household will now send a migrant whenever $\mathrm{U}_{\mathrm{SD}}-\mathrm{U}_{\mathrm{SS}}>0$ :

$$
\begin{aligned}
\mathrm{U}_{\mathrm{SD}}-\mathrm{U}_{\mathrm{SS}} & =\underbrace{\left(\frac{\bar{y}_{\mathrm{S}}+\alpha\left(\bar{y}_{\mathrm{D}}-c\right)}{1+\alpha}-\bar{y}_{\mathrm{S}}\right)}_{\Delta E\left(\tilde{y}^{N M}\right)}-k_{1} \underbrace{\left(\frac{\sigma_{S}^{2}+\alpha^{2} \sigma_{D}^{2}+2 \alpha \sigma_{S D}}{(1+\alpha)^{2}}-\sigma_{S}^{2}\right)}_{\Delta V\left(\tilde{y}^{N M}\right)}+ \\
& +\underbrace{\left(\frac{\alpha \bar{y}_{\mathrm{S}}+\left(\bar{y}_{\mathrm{D}}-c\right)}{1+\alpha}-\bar{y}_{\mathrm{S}}\right)}_{\Delta E\left(\tilde{y}^{M}\right)}-k_{2} \underbrace{\left(\frac{\alpha^{2} \sigma_{S}^{2}+\sigma_{D}^{2}+2 \alpha \sigma_{S D}}{(1+\alpha)^{2}}-\sigma_{S}^{2}\right)}_{\Delta V\left(\tilde{y}^{M}\right)}>0
\end{aligned}
$$

Here, as explained in section IIB, the terms characterize the change in expected earnings and in earnings variance from migration (with respect to non-migration) for both migrant and nonmigrant members of the household. The presence of a non-zero correlation between shocks in source and destination regions $\left(\sigma_{S D} \neq 0\right)$ does not substantially change the conditions under 
which the household gains from the migration of one of its members (see section III.B). It should be noted that the change in earnings variance for both the migrant $\left(\Delta V\left(\tilde{y}^{M}\right)\right)$ and the non-migrant $\left(\Delta V\left(\tilde{y}^{N M}\right)\right)$ now increases with the correlation $\sigma_{S D}$, with the first derivative being identical for both terms:

$$
\frac{\partial \Delta V\left(\tilde{y}^{M}\right)}{\partial \sigma_{S D}}=\frac{\partial \Delta V\left(\tilde{y}^{N M}\right)}{\partial \sigma_{S D}}=\frac{2 \alpha}{(1+\alpha)^{2}}>0
$$

In Figure 1, a positive (negative) correlation $\sigma_{S D}$ implies an upward (downward) shift in the intercepts of the functions $\Delta V\left(\tilde{y}^{M}\right)$ and $\Delta V\left(\tilde{y}^{N M}\right)$ and reduces (increases) the threshold values of $\sigma_{S}^{2}$ for which migration implies a reduction in earnings variance. In other words, if the shocks in source and destination regions are positively (negatively) correlated, migration will allow the household to reduce exposure to risk for lower (higher) values of $\sigma_{S}^{2}$, as compared to the case where the correlation is zero.

\section{A.II. Sample selection}

The fact that risk aversion is only observed for individuals who were present at home at the interview may bias our estimates if unobservables in the interview participation equation are correlated with risk aversion, conditional on observables. ${ }^{33}$ To address this concern we estimate the following sample selection model:

$$
\begin{gathered}
\text { wtRis } k_{i h k}^{*}=\mathbf{X}_{i h k}^{\prime} A+\mathbf{W}_{h k}^{\prime} B+\eta_{k}+e_{i h k} \\
i n t_{i h k}=1\left[y_{i h k}^{*}=\mathbf{X}_{i h k}^{\prime} C+\mathbf{W}_{h k}^{\prime} D+\boldsymbol{Z}_{i h k}^{\prime} E+\mu_{k}+u_{i h k} \geq 0\right]
\end{gathered}
$$

where $w t R i s k_{i h k}^{*}$ is the latent willingness to take risk and $i n t_{i h k}$ is a dummy equal one if the individual $i$ was at home at the interview (i.e. int $_{i h k}=1$ if the latent variable $y_{i h k}^{*} \geq 0$ ), so that:

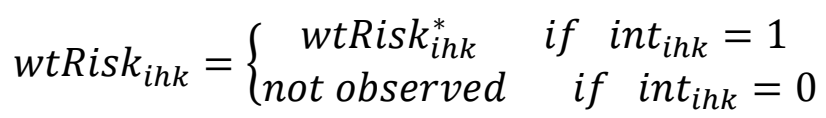

\footnotetext{
${ }^{33}$ Within the migrant population, individuals absent at the survey are more likely to be males, younger and less likely to be married.
} 
The vectors $\mathbf{X}_{i h k}^{\prime}$ and $\mathbf{W}^{\prime}{ }_{h k}$ collect the same observable individual-level covariates and family characteristics as in our main outcome equation (9), and $\eta_{k}$ and $\mu_{k}$ are county fixed effects. The selection equation is non-parametrically identified by the variable vector $\boldsymbol{Z}_{\text {ihk }}$ that includes major events in the families of interviewees such as pregnancies, births, illnesses, deaths, and that occurred in the months before or after the interview. ${ }^{34}$ These events, while arguably uncorrelated with risk attitudes, may have induced the individual to return to the home village, or to remain longer at home, and have hence affected the probability of being at home at the time of the interview. To test for selection, we estimate equation (A.11) using a probit model (thus assuming that $u_{i h k}$ is normally distributed) and construct the generalised residuals which we include in equation (A.10) (see Heckman 1978). A test of correlation between the unobservables determining participation and individual risk aversion corresponds to a simple t-test of whether the coefficient of the generalised residual is significantly different from zero. We report probit estimates of the first stage in the lower panel of Table A 2 where the dependent variable is the probability of being at home for the interview (which occurred between March and June 2009). The first four columns report estimates where we use events that occurred before the interview (during year 2008) as instruments, while the last four columns use events that occurred after the interview, but close enough to the interview date so that their occurrence could have been anticipated by families. The instruments are a dummy for a "pregnancy/birth" in the wider family (column 1 and 5), a dummy for "illness or death" (column 2 and 6), dummies for "pregnancy/birth" and "illness/death" (column 3 and 7) and a dummy for any of the events "pregnancy/birth/illness/death" (column 4 and 8). ${ }^{35}$ In all specifications, we condition on individual and household controls and on county fixed effects. As Table A 2

\footnotetext{
${ }^{34}$ We gather information about events from the 2009 and the 2010 surveys. The events recorded in the 2009 survey refer to year 2008 and, therefore, took place before the 2009 interview. The 2010 survey collected information on events taking place in the twelve months previous to the survey and on their month of occurrence. We combined this information to identify events that took place after the 2009 survey but by the end of year 2009. 35 The share of respondents reporting at least one event among pregnancy/birth, illness and death is $9.6 \%$ for year 2008 and $3.6 \%$ for year 2009 .
} 
shows, the occurrence of major life events in the months before the interview (columns 1-4) is a strong predictor for the probability of being at home at the time of interview. Events that happen after the interview (columns 5-8) are also significant in all regressions, although estimates are slightly less precise.

In the upper panel of Table A 2, we report the estimated coefficient on the generalised residuals (or inverse Mills ratios) that we have included in equation A.10. This coefficient is small (ranging from 1.2 and 2.6 percent of the average value of wtRisk in our sample) and not statistically different from zero in any of the specifications, with a coefficient/standard error ratio that is never larger than 0.35 . Thus, conditional on observables, individual risk attitudes are not correlated with unobservables that determine participation in the survey. 


\section{Appendix Figures}

FIGURE A1.- MAP OF RUMiC SURVEY

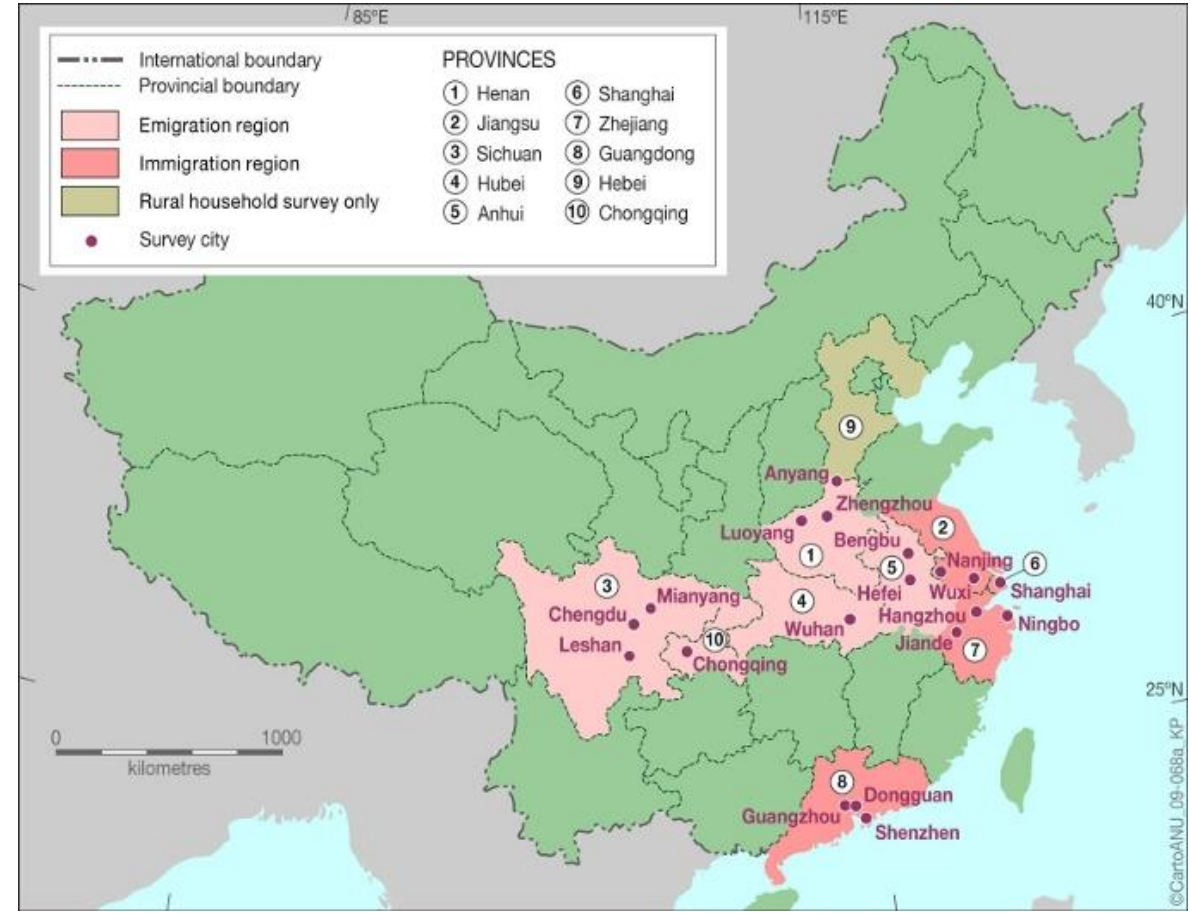

Note. The figure shows the provinces in which the RUMiC survey is conducted.

FIGURE A2.- DISTRIBUTION OF CHANGES IN SELF-REPORTED WILLINGNESS TO TAKE RISKS (2009 AND 2011 RUMIC-RHS WAVES)

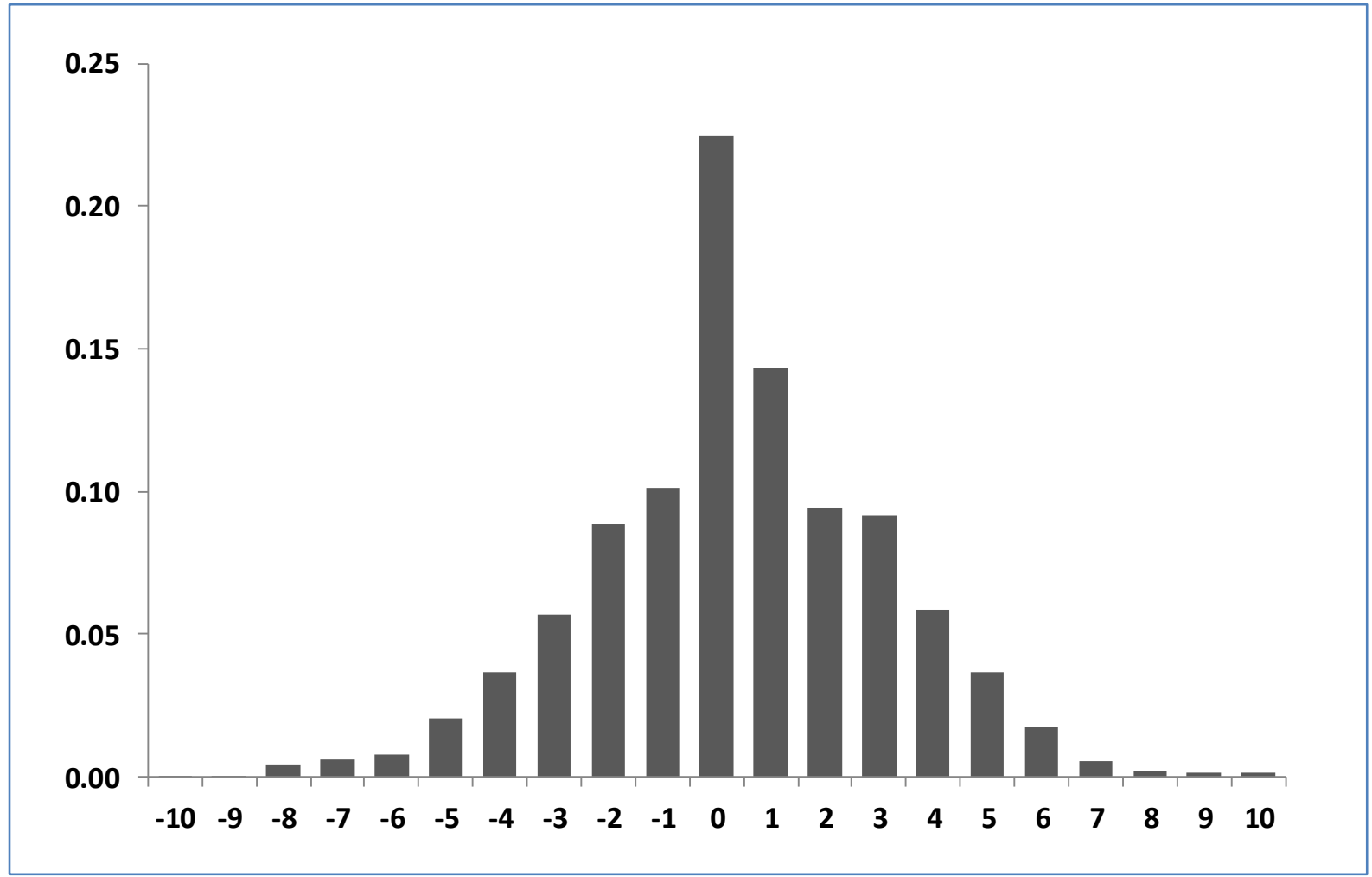

Note: The sample is composed of 2,906 individuals from our estimating sample who reported wtRisk in both waves. 


\section{Appendix Tables}

Table A1 - SAMPLE OF INDIVIDUALS IN RELEVANT HOUSEHOLDS VS ENTIRE SAMPLE

\begin{tabular}{|c|c|c|c|c|}
\hline & \multicolumn{2}{|c|}{ Entire sample } & \multicolumn{2}{|c|}{$\begin{array}{c}\text { At least } 2 \text { individuals } \\
\text { reporting wtRisk in } \\
\text { the } \mathrm{HH}\end{array}$} \\
\hline & Mean & Std. Dev. & Mean & Std. Dev \\
\hline \multicolumn{5}{|c|}{ Panel A - Individuals } \\
\hline Male & 0.51 & 0.50 & 0.51 & 0.50 \\
\hline Age & 40.4 & 12.16 & 40.6 & 12.15 \\
\hline Married & 0.82 & 0.38 & 0.83 & 0.37 \\
\hline Years of schooling & 7.4 & 2.76 & 7.4 & 2.78 \\
\hline Birth order & 2.2 & 1.31 & 2.2 & 1.28 \\
\hline Number of siblings & 3.0 & 1.64 & 3.0 & 1.61 \\
\hline Number of child & 1.5 & 1.08 & 1.5 & 1.06 \\
\hline Migrated last year & 0.22 & 0.41 & 0.20 & 0.40 \\
\hline Ever migrated & 0.35 & 0.48 & 0.32 & 0.47 \\
\hline Number of individuals & \multicolumn{2}{|c|}{17,658} & \multicolumn{2}{|c|}{7,808} \\
\hline \multicolumn{5}{|c|}{ Panel B - Households } \\
\hline Household size & 4.1 & 1.30 & 4.1 & 1.32 \\
\hline HH members aged $<16$ & 0.58 & 0.74 & 0.57 & 0.73 \\
\hline Hh members in the work force & 2.9 & 1.10 & 2.9 & 1.09 \\
\hline HH members aged $>60$ & 0.24 & 0.52 & 0.34 & 0.61 \\
\hline HH head's education (years) & 7.5 & 2.38 & 7.3 & 2.58 \\
\hline Plot size (Mu, $15 \mathrm{Mu}=1$ hectare) & 4.5 & 4.64 & 4.1 & 4.08 \\
\hline House value per capita (Yuan, in logs) & 9.1 & 1.32 & 9.2 & 1.33 \\
\hline Number of households & \multicolumn{2}{|c|}{6,425} & \multicolumn{2}{|c|}{2,961} \\
\hline
\end{tabular}

Note. The table compares characteristics of individuals in households in which more than one member in the labour force has reported risk attitudes with those of individuals in other households.

Source: 2009 RUMiC -RHS Survey. 
Table A 2 - SAMPLE SELECTION

\begin{tabular}{|c|c|c|c|c|c|c|c|c|}
\hline \multirow[b]{2}{*}{ Panel a) outcome $=w t$ Risk } & \multicolumn{4}{|c|}{ Events occurred in 2008} & \multicolumn{4}{|c|}{ Events occurred in 2009} \\
\hline & (1) & (2) & (3) & (4) & (5) & (6) & (7) & (8) \\
\hline \multirow[t]{2}{*}{ Inverse Mill's } & 0.054 & 0.043 & 0.032 & 0.032 & 0.053 & 0.065 & 0.063 & 0.067 \\
\hline & -0.187 & -0.185 & -0.186 & -0.186 & -0.193 & -0.194 & -0.194 & -0.194 \\
\hline Observations & 5893 & 5893 & 5893 & 5893 & 5627 & 5627 & 5627 & 5627 \\
\hline R-squared & 0.253 & 0.253 & 0.253 & 0.253 & 0.247 & 0.247 & 0.247 & 0.247 \\
\hline F-stat (Inverse Mills) & 0.08 & 0.06 & 0.03 & 0.03 & 0.07 & 0.11 & 0.1 & 0.12 \\
\hline Prob > F (Inverse Mills) & 0.7723 & 0.8145 & 0.8651 & 0.8634 & 0.7859 & 0.7377 & 0.746 & 0.73 \\
\hline Panel b) outcome = reporting wtRisk & (1) & (2) & (3) & (4) & (5) & (6) & (7) & (8) \\
\hline \multirow[t]{2}{*}{ Pregnancy/Birth } & $0.013^{* *}$ & & $0.013^{* *}$ & & $0.022^{* *}$ & & $0.021^{*}$ & \\
\hline & -0.006 & & -0.006 & & -0.011 & & -0.011 & \\
\hline \multirow[t]{2}{*}{ IIIness/death } & & $0.017^{* * *}$ & $0.017^{* * *}$ & & & $0.015^{*}$ & $0.015^{*}$ & \\
\hline & & -0.007 & -0.007 & & & -0.009 & -0.009 & \\
\hline \multirow[t]{2}{*}{ Pregnancy/Birth/IIIness/Death } & & & & $0.015^{* * *}$ & & & & $0.018^{* *}$ \\
\hline & & & & -0.005 & & & & -0.007 \\
\hline Observations & 6609 & 6609 & 6609 & 6609 & 6347 & 6347 & 6347 & 6347 \\
\hline Pseudo R-squared & 0.636 & 0.636 & 0.636 & 0.636 & 0.632 & 0.632 & 0.632 & 0.632 \\
\hline Chi2 $(x, N)$ & 3.4 & 4.77 & 7.74 & 6.21 & 1.88 & 1.91 & 3.53 & 3.83 \\
\hline Prob > chi2 & 0.0653 & 0.029 & 0.0208 & 0.0127 & 0.1709 & 0.1665 & 0.1713 & 0.0503 \\
\hline
\end{tabular}

Note. Panel B of the table reports marginal effects from probit regressions of a dummy that equals one if individuals reported risk attitude during the 2009 survey on indicators for a number of major life events having occurred to them and/or their relatives during 2008 or 2009. We define indicators for the following events or combinations of them: pregnancy/birth in 2008 (column 1 and 3), at least one illness or one death in 2008 (column 2 and 3), at least one pregnancy/birth, illness or death in 2008 (column 4), one pregnancy/birth in 2009 (column 5), at least one illness or death in 2009 (column 6), at least one pregnancy/birth, illness or death in 2009 (column 8). The sample includes all individuals (regardless of having reported risk attitudes or not) in the work force (i.e. aged between 16 and 60 and not currently in school or disabled) who live in households in which more than one member in the labour force has reported risk attitudes. Panel A reports estimates from OLS regressions of wtRisk on individual, household controls and the estimated Inverse Mill's Ratio. For each column, the inverse Mills ratio is computed using the instrument(s) reported in the lower panel of the table. All regressions include individual controls (age, age squared, a dummy for male, years of education, a dummy for being married, relation with the HH head dummies, number of siblings, order of birth, and number of children) household controls (household size and structure (number of family members under 16, in the work force, and older than 60); and per capita house value (in logs)) and county fixed effects. Robust standard errors are clustered at the household level and reported in brackets. $* * * \mathrm{p}<0.01, * * \mathrm{p}<0.05, * \mathrm{p}<0.1$. 
Table A3. - Individual MigRATIOn DeCision: Probit AND Logit Estimates (MARGinAl EFFECTS)

\begin{tabular}{|c|c|c|c|c|c|c|c|c|}
\hline & \multicolumn{4}{|c|}{ Probit } & \multicolumn{4}{|c|}{ Logit } \\
\hline & (1) & $(2)$ & (3) & (4) & (5) & (6) & (7) & (8) \\
\hline \multirow[t]{2}{*}{ wtRisk } & $0.013 * * *$ & $0.004 * *$ & $0.004^{* *}$ & $0.004^{* *}$ & $0.014^{* *}$ & $0.004 *$ & $0.003^{* *}$ & $0.004 * *$ \\
\hline & $(0.004)$ & $(0.002)$ & $(0.002)$ & $(0.002)$ & $(0.005)$ & $(0.002)$ & $(0.002)$ & $(0.002)$ \\
\hline Basic individual controls & & $x$ & $x$ & $x$ & & $x$ & $\mathrm{X}$ & $x$ \\
\hline Additional individual controls & & & $x$ & $x$ & & & $x$ & $x$ \\
\hline Household controls & & & & $x$ & & & & $x$ \\
\hline County fixed effects & $x$ & $x$ & $x$ & $x$ & $x$ & $x$ & $x$ & $x$ \\
\hline Observations & 6,332 & 6,332 & 6,103 & 5,992 & 6,332 & 6,332 & 6,103 & 5,992 \\
\hline R-squared & 0.232 & 0.386 & 0.400 & 0.409 & 0.234 & 0.391 & 0.404 & 0.414 \\
\hline
\end{tabular}

Note. The table shows the marginal effects derived using the probit (columns 1-4) and logit (columns 5-8) estimators of an individual indicator for migrants (in the previous year) on individual willingness to take risk (wtRisk) and other controls. The wtRisk variable measures individual willingness to take risks (decreasing with risk aversion) and has a mean of 2.57 and a standard deviation of 2.36. The basic individual controls are age, age squared, a dummy for male, years of education, and a dummy for married; the additional individual controls are: relation with $\mathrm{HH}$ head dummies, order of birth, number of siblings, and number of children; and the household controls are household size and structure (number of family members under 16, in the work force, and older than 60); and per capita house value (in logs). All regressions include 82 county fixed effects. The sample includes all individuals in the labour force (i.e. aged between 16 and 60 and not currently in school or disabled) who live in households in which more than one member in the labour force has reported risk attitudes. Robust standard errors are clustered at the household level and reported in brackets. $* * * \mathrm{p}<0.01, * * \mathrm{p}<0.05, * \mathrm{p}<0.1$. 
Table A4.- Individual MigRation Decision: Full SPECIFICATION

\begin{tabular}{|c|c|c|c|c|c|c|c|c|}
\hline & \multicolumn{4}{|c|}{ Migrated last year } & \multicolumn{4}{|c|}{ Ever migrated } \\
\hline & (1) & (2) & (3) & (4) & $(5)$ & (6) & (7) & $(8)$ \\
\hline \multirow[t]{2}{*}{ wtRisk } & $0.014^{* * *}$ & $0.005^{* * *}$ & $0.005^{* * *}$ & $0.005^{* * *}$ & $0.030 * * *$ & $0.014 * * *$ & $0.014^{* * *}$ & $0.014 * * *$ \\
\hline & $(0.0018)$ & $(0.0019)$ & $(0.0019)$ & $(0.0019)$ & $(0.0025)$ & $(0.0027)$ & $(0.0028)$ & $(0.0028)$ \\
\hline \multirow[t]{2}{*}{ Male dummy } & & $0.060 * * *$ & $0.081 * * *$ & $0.086^{* * *}$ & & $0.135^{* * *}$ & $0.132 * * *$ & $0.132 * * *$ \\
\hline & & $(0.0064)$ & $(0.0145)$ & $(0.0147)$ & & $(0.0087)$ & $(0.0178)$ & (0.0179) \\
\hline \multirow[t]{2}{*}{ Age } & & $-0.021 * * *$ & -0.005 & -0.004 & & $-0.020 * * *$ & $* 0.005$ & 0.003 \\
\hline & & $(0.0040)$ & $(0.0051)$ & $(0.0053)$ & & $(0.0046)$ & $(0.0059)$ & $(0.0060)$ \\
\hline \multirow[t]{2}{*}{ Age squared*100 } & & $0.015^{* * *}$ & 0.001 & -0.000 & & $0.009 *$ & $-0.015^{* *}$ & $-0.013^{* *}$ \\
\hline & & $(0.0044)$ & $(0.0055)$ & $(0.0056)$ & & $(0.0052)$ & $(0.0063)$ & $(0.0063)$ \\
\hline \multirow[t]{2}{*}{ Years of education } & & 0.001 & 0.001 & 0.001 & & 0.002 & 0.002 & 0.002 \\
\hline & & $(0.0014)$ & $(0.0014)$ & $(0.0014)$ & & $(0.0020)$ & $(0.0020)$ & $(0.0020)$ \\
\hline \multirow[t]{2}{*}{ Married } & & -0.032 & -0.044 & $-0.055^{*}$ & & -0.013 & -0.032 & -0.035 \\
\hline & & $(0.0274)$ & $(0.0289)$ & $(0.0286)$ & & $(0.0291)$ & $(0.0305)$ & $(0.0310)$ \\
\hline \multirow[t]{2}{*}{ Order of birth } & & & -0.002 & -0.003 & & & -0.002 & -0.002 \\
\hline & & & $(0.0028)$ & $(0.0027)$ & & & $(0.0043)$ & $(0.0043)$ \\
\hline \multirow[t]{2}{*}{ \# of siblings } & & & 0.002 & 0.001 & & & 0.003 & 0.003 \\
\hline & & & $(0.0027)$ & $(0.0027)$ & & & $(0.0040)$ & $(0.0040)$ \\
\hline \multirow[t]{2}{*}{ \# of children } & & & -0.002 & 0.001 & & & -0.008 & -0.005 \\
\hline & & & $(0.0059)$ & $(0.0057)$ & & & $(0.0079)$ & $(0.0080)$ \\
\hline \multirow[t]{2}{*}{ \# HH members below age 16} & & & & 0.009 & & & & 0.008 \\
\hline & & & & $(0.0059)$ & & & & $(0.0083)$ \\
\hline \multirow[t]{2}{*}{ \# HH members in work force } & & & & -0.005 & & & & $-0.011 *$ \\
\hline & & & & $(0.0040)$ & & & & $(0.0059)$ \\
\hline \multirow[t]{2}{*}{ \# HH members above age 60} & & & & -0.004 & & & & 0.009 \\
\hline & & & & $(0.0094)$ & & & & $(0.0130)$ \\
\hline \multirow[t]{2}{*}{ Ln (p.c. house value) } & & & & -0.002 & & & & 0.002 \\
\hline & & & & $(0.0034)$ & & & & $(0.0049)$ \\
\hline \multicolumn{2}{|l|}{ Relationship with $\mathrm{HH}$ head dummies } & & $\mathrm{x}$ & $\mathrm{x}$ & & & $\mathrm{X}$ & $\mathrm{x}$ \\
\hline County fixed effects & $\mathrm{x}$ & $\mathrm{x}$ & $\mathrm{x}$ & $x$ & $\mathrm{x}$ & $\mathrm{x}$ & $x$ & $x$ \\
\hline Observations & 6,332 & 6,332 & 6,103 & 5,992 & 6,280 & 6,280 & 6,052 & 5,946 \\
\hline R-squared & 0.187 & 0.288 & 0.305 & 0.310 & 0.148 & 0.273 & 0.288 & 0.292 \\
\hline
\end{tabular}

Note. The table reports estimates from LPM regressions of a dummy for individual migration status on individual willingness to take risk (wtRisk) and other controls. The migration status dummy equals one if the individual migrated for working reasons in the year before the interview (columns 1-4) or has ever migrated for working reasons (columns 5-8). The wtRisk variable measures individual willingness to take risks (decreasing with risk aversion) and has mean of 2.57 and a standard deviation of 2.36 . The basic individual controls are age, age squared, a dummy for male, years of education, and a dummy for married; the additional individual controls are: relation with $\mathrm{HH}$ head dummies, order of birth, number of siblings, and number of children; and the household controls are household size and structure (number of family members under 16, in the work force, and older than 60); and per capita house value (in logs). All regressions include 82 county fixed effects. The sample includes all individuals in the labour force (i.e. aged between 16 and 60 and not currently in school or disabled) who live in households in which more than one member in the labour force has reported risk attitudes. Robust standard errors are clustered at the household level and reported in brackets. $* * * \mathrm{p}<0.01, * * \mathrm{p}<0.05, * \mathrm{p}<0.1$. 


\begin{tabular}{lcccccc}
\hline \hline & \multicolumn{3}{c}{ Migrated last year } & \multicolumn{3}{c}{ Ever migrated } \\
& $(\mathbf{1})$ & $\mathbf{( 2 )}$ & $\mathbf{( 3 )}$ & $\mathbf{( 4 )}$ & $\mathbf{( 5 )}$ & $\mathbf{( 6 )}$ \\
\hline wtRisk & $0.005^{* * *}$ & $0.006^{* * *}$ & $0.006^{* * *}$ & $0.014^{* * *}$ & $0.014^{* * *}$ & $0.014^{* * *}$ \\
& $(0.002)$ & $(0.002)$ & $(0.002)$ & $(0.003)$ & $(0.003)$ & $(0.003)$ \\
height (cm) & & -0.001 & -0.001 & & 0.001 & 0.001 \\
& & $(0.001)$ & $(0.001)$ & & $(0.001)$ & $(0.001)$ \\
weight (kg) & & $0.001^{*}$ & $0.001^{*}$ & & 0.000 & 0.000 \\
& & $(0.001)$ & $(0.001)$ & & $(0.001)$ & $(0.001)$ \\
health_poor & & & $0.112^{* * *}$ & & & $0.186^{* * *}$ \\
& & & $(0.042)$ & & & $(0.057)$ \\
health_average & & & $0.129^{* * *}$ & & & $0.229^{* * *}$ \\
& & & $(0.041)$ & & & $(0.053)$ \\
health_good & & & $0.138^{* * *}$ & & & $0.234^{* * *}$ \\
& & & $(0.041)$ & & & $0.053)$ \\
health_very good & & & $0.154^{* * *}$ & & & $(0.054)$ \\
\hline Individual and HH controls & $\mathrm{X}$ & $\mathrm{X}$ & $\mathrm{X}$ & $\mathrm{X}$ & $\mathrm{X}$ & $\mathrm{X}$ \\
County fixed effects & $\mathrm{X}$ & $\mathrm{X}$ & $\mathrm{X}$ & $\mathrm{X}$ & $\mathrm{X}$ & $\mathrm{X}$ \\
\hline Observations & 5,992 & 5,941 & 5,941 & 5,946 & 5,895 & 5,895 \\
R-squared & 0.310 & 0.311 & 0.313 & 0.292 & 0.293 & 0.295 \\
\hline \hline
\end{tabular}

Note. The table tests the robustness of wtRisk coefficient to the inclusion of further individual health-related characteristics: height, weight, and a set of dummies for self-reported health status (the category "very poor" is excluded). The migration dummy equals one if the individual migrated for work in the year before the interview (columns 1-3) or had ever migrated for work (columns 4-6). Individual controls are age, age squared, a dummy for male, years of education, a dummy for married, relation with HH head dummies, order of birth, number of siblings, and number of children; the household controls are household size and structure (number of family members under 16, in the work force, and older than 60); and per capita house value (in logs). All regressions include 82 county fixed effects. The sample includes all individuals in the labour force (i.e. aged between 16 and 60 and not currently in school or disabled) who live in households in which more than one member in the labour force has reported risk attitudes. Robust standard errors are clustered at the household level and reported in brackets.. *** $\mathrm{p}<0.01, * * \mathrm{p}<0.05, * \mathrm{p}<0.1$. 
Table A6.- Changes In SElF-RePORTED WiLlingness to TAKe Risks (2009-2011 RUMiCRHS WAVES)

\begin{tabular}{|c|c|c|c|c|c|c|c|c|}
\hline & \multicolumn{4}{|c|}{ Change in wtRisk 2009-2011 } & \multicolumn{4}{|c|}{ wtRisk 2011} \\
\hline & (1) & (2) & (3) & (4) & (5) & (6) & (7) & (8) \\
\hline & \multicolumn{8}{|c|}{ Panel A } \\
\hline \multirow[t]{2}{*}{ Migration in 2010} & 0.037 & 0.120 & 0.106 & 0.108 & 0.151 & -0.059 & -0.088 & -0.093 \\
\hline & $(0.232)$ & (0.239) & $(0.245)$ & $(0.244)$ & $(0.192)$ & (0.196) & (0.201) & (0.201) \\
\hline \multirow[t]{2}{*}{ Observations } & 2,906 & 2,906 & 2,813 & 2,791 & 2,906 & 2,906 & 2,813 & 2,791 \\
\hline & \multicolumn{8}{|c|}{ Panel B } \\
\hline \multirow[t]{2}{*}{ Migration only in 2010} & -0.121 & -0.027 & -0.032 & -0.013 & 0.056 & -0.164 & -0.192 & -0.199 \\
\hline & $(0.303)$ & $(0.307)$ & $(0.316)$ & $(0.315)$ & $(0.261)$ & $(0.263)$ & $(0.270)$ & $(0.269)$ \\
\hline \multirow[t]{2}{*}{ Migration in 2008 and 2010} & 0.195 & 0.267 & 0.242 & 0.227 & 0.246 & 0.045 & 0.015 & 0.011 \\
\hline & $(0.319)$ & $(0.325)$ & $(0.333)$ & $(0.331)$ & $(0.257)$ & $(0.255)$ & $(0.261)$ & $(0.261)$ \\
\hline Observations & 2,906 & 2,906 & 2,813 & 2,791 & 2,906 & 2,906 & 2,813 & 2,791 \\
\hline wtRisk 2009 & & & & & $\mathrm{X}$ & $\mathrm{X}$ & $\mathrm{X}$ & $\mathrm{X}$ \\
\hline Basic individual controls & & $x$ & $x$ & $x$ & & $x$ & $x$ & $x$ \\
\hline Additional individual control & & & $x$ & $x$ & & & $x$ & $x$ \\
\hline Household controls & & & & $x$ & & & & $x$ \\
\hline County fixed effects & $\mathrm{x}$ & $\mathrm{x}$ & $\mathrm{x}$ & $\mathrm{x}$ & $\mathrm{x}$ & $\mathrm{x}$ & $\mathrm{x}$ & $\mathrm{x}$ \\
\hline
\end{tabular}

Note. This table tests the relationship between changes in self-reported risk attitudes between 2009 and 2011 and migration experience in 2010. In columns 1-4, the dependent variable is the change in self-reported willingness to take risks between the 2009 and the 2011 waves, while in columns 5-8 the dependent variable is self-reported willingness to take risks in 2011. In Panel A, the main regressor of interest is an indicator for the individual being recorded as migrant in year 2010. In Panel B, the main regressors of interest are an indicator for the individual having migrated only in 2010 and an indicator for having migrated in both 2008 and 2010. In Panel B, willingness to take risks reported in 2009 is always included in the controls. The basic individual controls are age, age squared, a dummy for male, years of education, and a dummy for married; the additional individual controls are: relation with $\mathrm{HH}$ head dummies, order of birth, number of siblings, and number of children; and the household controls are household size and structure (number of family members under 16, in the work force, and older than 60); and per capita house value (in logs). All regressions include 82 county fixed effects. The sample includes all individuals in our estimating sample who also reported risk attitudes in the 2011 wave. Robust standard errors are clustered at the household level and reported in brackets. $* * * \mathrm{p}<0.01, * * \mathrm{p}<0.05, * \mathrm{p}<0.1$. 
Table A7.- Risk AtTitudes AND FUtURE MigRATION DECISIONS

\begin{tabular}{lccccccccc}
\hline \hline & \multicolumn{3}{c}{$\begin{array}{c}\text { First migration in 2009 or later - } \\
\text { after risk measurement }\end{array}$} & \multicolumn{4}{c}{$\begin{array}{c}\text { Migration last year (2008) - } \\
\text { before risk measurement }\end{array}$} \\
Age range & $\mathbf{1 6 - 3 2}$ & $\mathbf{1 6 - 3 4}$ & $16-36$ & $16-60$ & $16-32$ & $16-34$ & $16-36$ & $16-60$ \\
& $(1)$ & $(2)$ & $(3)$ & $(4)$ & $(5)$ & $(6)$ & $(7)$ & $(8)$ \\
\hline wtRisk & $0.014^{* *}$ & $0.016^{* * *}$ & $0.014^{* * *}$ & $0.003^{* *}$ & $0.015^{* *}$ & $0.012^{* *}$ & $0.010^{* *}$ & $0.005^{* * *}$ \\
& $(0.007)$ & $(0.006)$ & $(0.005)$ & $(0.002)$ & $(0.007)$ & $(0.006)$ & $(0.005)$ & $(0.002)$ \\
\hline Individual \& HH controls & $\mathrm{X}$ & $\mathrm{X}$ & $\mathrm{X}$ & $\mathrm{X}$ & $\mathrm{X}$ & $\mathrm{X}$ & $\mathrm{X}$ & $\mathrm{X}$ \\
County fixed effects & $\mathrm{X}$ & $\mathrm{X}$ & $\mathrm{X}$ & $\mathrm{X}$ & $\mathrm{X}$ & $\mathrm{X}$ & $\mathrm{X}$ & $\mathrm{X}$ \\
\hline Observations & 395 & 509 & 665 & 3,979 & 924 & 1,117 & 1,370 & 5,992 \\
R-squared & 0.58 & 0.50 & 0.43 & 0.15 & 0.48 & 0.46 & 0.44 & 0.31 \\
\hline \hline
\end{tabular}

Note. This table tests whether self-reported risk attitudes measured at the beginning of year 2009 predict successive first-time migration decisions. In columns 1-4 the dependent variable is an indicator for the individual having migrated for the first time in year 2009, 2010 or 2011, while in columns 5-8 the dependent variable is the usual indicator for having migrated last year, i.e. in year 2008. Individual controls are age, age squared, a dummy for male, years of education, a dummy for married, relation with HH head dummies, order of birth, number of siblings, and number of children; the household controls are household size and structure (number of family members under 16, in the work force, and older than 60); and per capita house value (in logs). All regressions include 82 county fixed effects. The sample includes all individuals in our estimating sample who also reported information about the year of first migration, and whose age is below the indicated threshold. Robust standard errors are clustered at the household level and reported in brackets. $* * * \mathrm{p}<0.01, * * \mathrm{p}<0.05, * \mathrm{p}<0.1$. 
Table A8.- Migration DURATION AND Risk AtTITUdEs (RUMiC URBAN SURVEYS)

\begin{tabular}{lcc}
\hline & OLS & Fixed Effects \\
& (1) & (2) \\
\hline Years since first migration & 0.006 & -0.002 \\
& $(0.004)$ & $(0.007)$ \\
\hline Individual controls & $X$ & $X$ \\
Year and city dummies & $X$ & $X$ \\
Individual fixed effects & & $X$ \\
\hline Observations & 22,208 & 22,208 \\
R-squared & 0.132 & 0.013 \\
\hline
\end{tabular}

Note. This table tests the relationship between attitude toward risks and the length of migration experience. It reports estimates of wtRisk on years since first migration for a sample of migrants living in urban areas. Individual controls are age, age squared, a dummy for male, years of education, a dummy for married and the number of cities the individual has migrated to. OLS estimates are presented in column 1 while estimates including individual fixed effects are presented in column 2. The sample is an unbalanced panel of rural-urban migrants living in urban areas coming from six waves (from 2008 to 2013) of the urban module of the RUMiC Survey. Robust standard errors are clustered at the household level and reported in brackets. $* * * \mathrm{p}<0.01, * * \mathrm{p}<0.05, * \mathrm{p}<0.1$. 
Table A9.- WithIN HousEHOLD SELECTION: HH FIXED EFFECTS

\begin{tabular}{lccc}
\hline \hline & (1) & (2) & (3) \\
\hline wtRisk & $\begin{array}{c}0.005^{* * *} \\
(0.002)\end{array}$ & $\begin{array}{c}0.016^{* * *} \\
(0.005)\end{array}$ & \\
Dummy for highest wtRisk in HH & & & $\begin{array}{c}0.028^{* *} \\
(0.013)\end{array}$ \\
\hline Individual controls & & & $\mathrm{X}$ \\
Household controls & $\mathrm{X}$ & $\mathrm{X}$ & \\
Household fixed effects & $\mathrm{X}$ & & $\mathrm{X}$ \\
County fixed effects & & $\mathrm{X}$ & \\
\hline Observations & $\mathrm{X}$ & & 5,992 \\
R-squared & 5,992 & 5,992 & 0.678 \\
\hline \hline
\end{tabular}

Note. The table reports the estimates from LPM regressions of a dummy for individual migration status (in the previous year) on different measures of willingness to take risks, other controls and household fixed effects. The individual controls are age, age squared, a dummy for male, years of education, a dummy for married, relation with $\mathrm{HH}$ head dummies, order of birth, number of siblings, and number of children; and the household controls are household size and structure (number of family members under 16, in the work force, and older than 60); and per capita house value (in logs). The sample includes all individuals in the work force (i.e. aged between 16 and 60 and not currently in school or disabled) who live in households in which more than one member in the work force has reported risk attitudes. Robust standard errors are clustered at the household level and reported in brackets. $* * * \mathrm{p}<0.01, * * \mathrm{p}<0.05, * \mathrm{p}<0.1$. 
Table A 10 - ACROSS HOUSEHOLD MIGRATION DECISION - SHARE OF MIGRANTS

\begin{tabular}{|c|c|c|c|c|c|}
\hline \multirow{2}{*}{ HH_avg_wtRisk } & & (1) & (2) & (3) & (4) \\
\hline & & $\begin{array}{l}0.005^{* *} \\
(0.002)\end{array}$ & $\begin{array}{l}0.001 \\
(0.002)\end{array}$ & & \\
\hline \multicolumn{2}{|c|}{ HH_range_wtRisk } & & $\begin{array}{l}0.009 * * * \\
(0.002)\end{array}$ & & \\
\hline \multicolumn{2}{|l|}{ HH_max_wtRisk } & & & $\begin{array}{c}0.008^{* * *} \\
(0.002)\end{array}$ & $\begin{array}{c}0.012 * * * \\
(0.003)\end{array}$ \\
\hline \multicolumn{2}{|l|}{ HH_oth_wtRisk } & & & $\begin{array}{r}-0.005 \\
(0.003)\end{array}$ & $\begin{array}{c}-0.010 * * \\
(0.005)\end{array}$ \\
\hline \multicolumn{2}{|c|}{ Household controls } & $x$ & $x$ & $\mathrm{X}$ & $\mathrm{X}$ \\
\hline \multicolumn{2}{|c|}{ County fixed effects } & $\mathrm{X}$ & $\mathrm{x}$ & $\mathrm{X}$ & $\mathrm{x}$ \\
\hline WF age range: & $\begin{array}{l}16-60 \\
16-50\end{array}$ & $x$ & $\bar{X}$ & $X$ & $\mathrm{X}$ \\
\hline \multicolumn{2}{|l|}{ Observations } & 2,961 & 2,961 & 2,961 & 2,189 \\
\hline \multicolumn{2}{|l|}{ R-squared } & 0.281 & 0.285 & 0.284 & 0.374 \\
\hline
\end{tabular}

Note. The table reports estimates from OLS regressions of the share of household members in the work force sent as migrants on different household-level measures of willingness to take risks and other controls. The variables HH_avg_WtRisk and HH_range_wtRisk measure the average and the range of willingness to take risks in the household, respectively. The variables $H H_{-} \max _{-} w t R i s k_{h k}$ and $H H_{-}$oth_wtRisk $k_{h k}$ measure the risk preferences of the individual with the highest willingness to take risks in the household and the average risk attitudes among the other household members, respectively. Columns 1 and 2 replicate columns 3 and 4 in Table 4; while columns 3 and 4 replicate columns In columns $1-4$, the age bracket for workers to be considered part of the workforce is 16-60; in columns 5-6 it is 16-50. The household controls are household size and structure (number of family members under 16, in the work force, and older than 60); per capita house value (in logs); size of the family plot; and the years of education and age of the head of household. All specifications include 82 county fixed effects. The sample includes all households in which at least two individuals have reported risk attitudes, and at least one of these is in the labour force (i.e. aged between 16 and 60 and not currently in school or disabled). Robust standard errors are reported in brackets. $* * * \mathrm{p}<0.01, * * \mathrm{p}<0.05, * \mathrm{p}<0.1$. 